JOSEPH FARRELL

University of California at Berkeley

C A R L SHA P I RO

University of California at Berkeley

\title{
Standard Setting in High-Definition Television
}

TODAY TELEVISION SIGNALS are encoded, broadcast, and received in the United States using the color system of the National Television Systems Committee (NTSC). Almost 40 years old, this system has well-known performance limitations. It is subject to flickering and ghosting, it has low resolution (more apparent as TV sets become larger), and it requíres cutting off the side panels in showing material shot for exhibition on wide movie screens. NTSC is derisively known in some circles as " Never Twice the Same Color.' Although it nominally has 525 horizontal lines, a mere 483 "active" lines produce the picture; the rest carry auxiliary information. Moreover, NTSC is interlaced: only half of the lines are displayed on each pass. This creates a visible flicker when there are horizontal lines in the scene portrayed, so studios deliberately reduce the resolution. Even with ideal reception, the resolution is roughly equivalent to that achievable with 330 to 350 lines. The PAL and SECAM standards are significantly better, but still noticeably imperfect. Developed about 15 years later than NTSC, they are used in much of the world outside North America and Japan.

We thank the National Science Foundation (SES 8821529), and Carl Shapiro thanks the Consortium on Competition and Cooperation for financial support. Both authors are indebted to David Cooper and Kathryn Graddy at Princeton, Margaret Miller at Berkeley, and Sam Farrell for research assistance and to Stanley Besen, Peter Fannon, Richard Gilbert, Bronwyn Hall, Paul Klemperer, Richard Nelson, Roger Noll, Michael Riordan, Greg Rosston, Suzanne Scotchmer, and Larry Thorpe for helpful comments. Errors of fact, interpretation, or algebra are our own responsibility. 


\section{The Promise and Lure of HDTV}

High-definition television is a major technical improvement over these systems. HDTV claims to offer a picture quality equivalent to 35 millimeter film by using roughly 1,000 lines. It has vastly improved sound quality, equivalent to compact disks. Perhaps most important of all, HDTV has a screen aspect ratio (the ratio of the screen's width to its height) of 16:9 compared with NTSC's 4:3. A wider screen reduces the "picture in a box" feeling of current television and allows standard 35 millimeter movies to be viewed uncropped. The higher resolution permits much closer viewing (without unacceptably obvious lines and pixels) than does NTSC, so the viewer feels more "in the scene.", I

The adoption of HDTV must be studied as the adoption of a system involving several components, which together can meet HDTV's informational requirements. HDTV signals contain much more information than do NTSC signals. HDTV thus requires a transmission and reception system able to convey this greater flow of image and sound information. This system will be the result not only of technical agreements about how to do things, but also of many investments by programming producers, receiver manufacturers, broadcasters, and householders. The key components of this system are (1) a standard or format for HDTV signals; (2) programming in the HDTV format; (3) transmission equipment capable of delivering the HDTV signal into the household; and (4) television sets capable of receiving and displaying the HDTV signal. ${ }^{2}$

\section{Key Economic Issues}

Our study of HDTV has two aspects: standard selection and adoption. Standard selection is the process by which a nation's HDTV standard

1. Allegedly, the higher resolution also makes it more desirable to have a large screen, so that HDTV technology is complementary with large-screen manufacturing and, prospectively, with flat-screen technology (which will enable householders to have truly large screens without enormous boxes). See, for instance, Office of Technology Assessment (1990).

2. Other components include studio production equipment and videotape machines. 
is chosen. Adoption is the process by which HDTV hardware and production practices will replace existing equipment and practices. Of course, these two areas are related: in particular, a poorly chosen standard will retard or preclude adoption of HDTV. But standard selection is (in HDTV) primarily a decision problem, while adoption is a market process.

\section{Standard Selection}

Choosing an HDTV standard raises several economic issues. First, what "procedure" for choosing a standard works well? A procedure could be anything from complete reliance on market forces to an early, centralized choice of a standard. The procedure used will determine which system is chosen, when it is chosen, and how the hardware embodying that system will be made available. In some standards markets-less centrally controlled than television - a marketplace rivalry could arise between several competing systems to develop a bandwagon and thus become the standard. In HDTV, however, there will almost certainly be no such ex post rivalry. In the United States it might arise if nonbroadcast media adopt a standard that differs from the broadcast standard chosen by the Federal Communications Commission (FCC), but this seems increasingly unlikely.

In picking an HDTV standard, Japan and the European Community have followed a much more centralized approach than has the United States. Although the U.S. process may seem painfully prolonged, it has injected into HDTV some of the benefits of competition that have been absent in Europe and Japan. Our theoretical treatment of standardsetting procedures is meant to point out some of the benefits and problems of alternative approaches in general; it is probably too late for practical policy suggestions, since both Japan and Europe have already picked standards, and the United States has already put into place a formal standard-setting procedure.

Second, how should a nation balance the vested interests of incumbent broadcasters and owners of receivers against what would be the best course of action if it were starting from scratch? This is related to a question treated in the theoretical literature on technology adoption with network externalities: does the market exhibit excess inertia (a 
bias toward established technologies over new and superior ones) or insufficient friction (a bias toward new but incompatible technologies) ? ${ }^{3}$ In the context of HDTV standard setting, however, two specific policy issues arise in this regard that are not treated in the excess-inertia literature. Should HDTV be designed to accommodate terrestrial broadcasting? And should set owners be protected from stranding (for example, by requiring the continued broadcast of NTSC signals)?

To date, the FCC has been strikingly concerned with protecting the interests of terrestrial broadcasters by trying to ensure that they will be able to participate in HDTV, even when this goal conflicts with the ostensible goal of promoting HDTV and with the rational management of scarce spectrum. (Of course, we are not the first to note terrestrial broadcasters' great political influence over the FCC, whether by "capture' at the agency level or through political influence in Congress.) Implicitly, the FCC's approach reflects a greater concern about stranding and insufficient friction than about any dangers that excess inertia will retard the adoption of HDTV. The FCC has chosen to protect the interests of terrestrial broadcasters by deciding to pick an HDTV standard whose signals can fit into the existing terrestrial broadcast spectrum slots. As a consequence, the technical quality of HDTV in the United States may be compromised and its cost increased, and American HDTV will use large amounts of scarce spectrum space, arguably creating a significant social inefficiency.

In this paper we focus on the standard-setting process currently taking place under FCC auspices. Broader influences, however, may prove to be significant. First, if the FCC decided to do something very unpopular, Congress could override its decision. Second, the entire FCC standardsetting process may be irrelevant, left behind by the whirlwind of technological progress. Advances in computer graphics, or the laying of fiber-optic cables into homes, may relegate FCC-style HDTV to oblivion.

\section{Adoption of HDTV}

For HDTV to succeed, a chicken-and-egg problem must be solved. More precisely, HDTV programming must be available, HDTV signals

3. Farrell and Saloner (1986); and Katz and Shapiro (1986a, 1986b). 
must be delivered to the home, and consumers must purchase HDTV receivers and videotape machines. The provision of programming is unlikely to be a bottleneck, but the other two factors may be.

Consumers will find HDTV sets expensive, according to current estimates and to market prices now prevailing in Japan. In the United States local broadcasters (who serve much smaller markets than the satellite services in Japan and in Europe can serve) will find the cost of HDTV transmission equipment a major deterrent. The market may not find HDTV worth the extra expense, at least until hardware prices fall dramatically. This is especially so because NTSC is not a stationary target; significant improvements can be made to NTSC without the big costs and the dislocations involved in adopting HDTV. These simple improvements, while not of HDTV quality, may stymie the adoption of the more advanced system.

No one can safely predict the timing of HDTV adoption. Estimates of the costs of HDTV receivers are unreliable, and consumers' willingness to pay for HDTV is unknown. But we doubt that many Americans will see HDTV in their homes in this millennium.

Although we are bearish on short-term prospects for HDTV adoption, it does seem likely that in the long term, once costs fall enough, the technology will triumph. By examining the adoption of color television and by using a theoretical model of HDTV adoption, we can gain valuable insights into the likely adoption process for HDTV. Our concern here is not with the precise timing of HDTV set purchases, but with understanding how policy decisions made in picking an HDTV standard are likely to influence that timing.

\section{HDTV and U.S. Competitiveness}

Much of what is written on HDTV is about industrial policy and competitiveness, not about standard setting per se. How important is HDTV for the survival of the consumer electronics industry in the United States, and how important is that survival for U.S. economic welfare? What spillovers might U.S. manufacturers enjoy from HDTV leadership? And so on. ${ }^{4}$ We do not directly discuss industrial policy;

4. See, for example, Senate Committee on Governmental Affairs (1989) and many of the articles in Rice (1990). 
indeed, we doubt that HDTV is much more "strategic"' than a number of other industries. Instead, we see HDTV as a case study of centralized technology selection, a high-stakes example of a general problem: how to pick a single version of a promising new technology when multiple incompatible versions are available but ordinary marketplace rivalry is (at least arguably) undesirable.

Yet we think our analysis could be useful in the industrial policy side of the HDTV debate. For example, our discussion of the likely rewards to the proponent whose HDTV system is picked as the standard will certainly be relevant to those who place great weight on the winner's nationality (somehow defined).

To give another example, we discuss below the relatively decentralized, and relatively slow, standard-setting procedure being used in the United States. One cost of delay may be that foreign firms will gain an edge over U.S. television manufacturers (which means Zenith, if one judges by ownership) by moving down a learning curve manufacturing HDTV equipment, if Zenith is somehow barred from producing sets for foreign HDTV. If learning effects are marked, this could be important for subsequent competition and the distribution of rents.

Finally, however, and against the spirit of much of the industrial policy literature on HDTV, we note that the Japanese may have won a Pyrrhic victory in pioneering HDTV since their analog system will very likely be inferior to an all-digital U.S. system-just as the American NTSC standard, which was the first color TV standard developed and implemented, is technically worse than the other color standards, PAL and SECAM.

\section{International Development of HDTV}

In this section we summarize the international development of HDTV to date, emphasizing the Japanese and European procedures for selecting HDTV formats.

\section{Japan as the HDTV Pioneer}

Although the possibility of improving on NTSC must have been evident almost from its first days, and some U.S. firms worked on high- 
resolution systems, the first HDTV system was developed, beginning in the late 1960s, in Japan. Nippon Hoso Kyokai (NHK), the Japanese public broadcasting company, proposed an HDTV research program to the Comite Consultatif International de Radio (CCIR), the organ of the International Telecommunications Union that deals with broadcast standards and international spectrum allocation. NHK began experimental transmissions of HDTV in $1979 .^{5}$

Like any TV system, HDTV requires the coordinated introduction of several complementary components: studio or production equipment, programming, transmission systems, and receivers. The Japanese government coordinated and to some degree subsidized the development of a variety of technologies needed for these components. Development of the basic HDTV technology cost NHK approximately $\$ 150$ million. Including the cost of development of related technologies, Japanese firms and the government may have spent as much as $\$ 1.3$ billion.

Out of this effort came a high-definition system, HiVision, that has been broadcasting over Japan since June 1989 at a demonstration level of an hour a day. During November 1991 it began broadcasting eight hours a day. HiVision has 1,125 lines (1,035 active lines), yielding over twice the resolution of the 483 active lines of NTSC.

Partly because they picked a proponent and an approach early in the development process, the Japanese have been moving ahead much faster than either the Europeans or the Americans with commercializing HDTV. NHK estimates that by 1997 , HiVision transmissions will account for one-sixth of all broadcasts, and almost half by the year $2000 .{ }^{6}$ The FCC will not even choose a standard before late 1993.

Until recently, HDTV receivers in Japan were very expensive$\$ 15,000$ to $\$ 30,000 .^{7}$ (These prices may have been for the very large receivers used in department stores and other public places to display the hour-a-day demonstration broadcasts.) The first hope for selling to ordinary consumers was the recent introduction by Sharp of a 36-inch

5. The information in this paragraph and the next is primarily from Office of Technology Assessment (1990).

6. Michael Selwyn, "The Big Picture Comes to Asia," Asian Business 26 (February 1990):51.

7. Neil Gross, “Japan's HDTV: What's Wrong with This Picture?" Business Week, April 1, 1991, p. 80. 
set for about $\$ 8,000 .{ }^{8}$ This price is much more than top-of-the-line NTSC sets, but in real terms it is only around twice the initial price of color sets in the United States $(\$ 1,000$ in 1954).

The price of receivers, however, is not the only threat to the adoption of HiVision. Many independent Japanese broadcasters are apparently resisting HDTV. They prefer to use ClearVision, an enhanced-definition television (EDTV) system developed by the Broadcast Technology Association. ${ }^{9}$ We will say more later about the EDTV threat to HDTV.

\section{Basic Approaches to HDTV Development}

In developing HDTV technology, Japan, Europe, and the United States have addressed a thorny question: To what extent should HDTV be regarded as an improvement of the existing TV system, and to what extent should it be viewed as a new service that will, if successful, replace the existing system? While imprecise, this question raises two issues.

First is the issue of compatibility. Can an existing (NTSC) receiver produce a picture from an HDTV signal, and can an HDTV receiver produce a picture from an NTSC signal? A compatible technology can be adopted with much less coordinating effort than one that is incompatible. On the other hand, compatibility constrains the design of the system, thus raising costs, lowering performance, or both. NHK apparently viewed HDTV as a new service and chose not to make HiVision directly compatible with NTSC: without an adapter, existing receivers cannot produce any picture from a HiVision signal. ${ }^{10}$ (HiVision is also incompatible with PAL and SECAM, the color TV standards in use in most of the world outside North America and Japan.) Manufacturers,

8. "Sharp Cuts Price of Advanced TV," New York Times, February 1, 1992, p. 21.

9. EDTV is sometimes referred to as extended-definition television. It is a TV technology that is a marked improvement over existing systems such as NTSC. Unlike improveddefinition television (IDTV), EDTV requires a change in broadcast format (normally maintaining compatibility with the existing system). The quality of EDTV is poorer than that of HDTV.

10. According to one report, Mitsubishi has produced a down-converter that costs about $\$ 150$. It enables an NTSC receiver to produce a picture from a HiVision broadcast. Shin Kusonoki and Masaki Ichikawa, "A Broadcasting Delay," Electronics 63 (October 1990):52. Many owners of NTSC sets probably would resist even a modest expenditure for a converter, as they did after the 1950 adoption of the incompatible CBS color standard in the United States. For a theory of costly and imperfect converters, see Farrell and Saloner (1992). 
however, are choosing to make HiVision receivers in such a way (effectively bundling a converter) that they can receive NTSC signals. ${ }^{11}$

Second is the issue of spectrum use. Spectrum suitable for terrestrial broadcast is scarce. Consequently, if one thinks of HDTV as a new service, it is natural as well as wise to use another transmission medium, such as cable or satellite. NHK designed HiVision for direct broadcast from satellite (DBS). If HDTV is considered an enhancement to existing service, it seems more natural to preserve the old distribution medium.

The Japanese approach to HDTV, compared with the European and U.S. approaches, has been less respectful of established interestsnotably in its policy on compatibility with existing receivers. The Japanese approach also has been more centralized. There was an ex ante decision to develop a particular system. It was developed with little, if any, competitive spur, but with considerable central coordination and subsidies. The U.S. approach has been in some ways the most controlled by established interests-notably existing broadcasters-and the technology development has been the most decentralized. The Europeans have been intermediate on both counts.

\section{Efforts to Choose a World Production Standard}

Surprisingly, it seems that no newsworthy attempts have been made to adopt a world standard for HDTV transmission. ${ }^{12}$ Perhaps everyone recognized that such an attempt would be doomed. But even if transmission standards could not be agreed upon, a worldwide production standard might have been set. Then studios throughout the world could use compatible equipment, and only at the broadcasting stage would incompatibilities be introduced. There would be economies of scale in producing studio equipment, and trade in programming would be facilitated.

There are links between production and transmission standards. Transmission is much easier if certain parameters are chosen in a co-

11. Because the first adopters of HDTV technology will constitute a small "network," while those who remain with NTSC will be a large network, the former consumers will be more likely to buy converters if converters in each direction are available at comparable prices. This is especially true in the HDTV case as a result of the FCC's decision to protect from stranding the owners of NTSC sets.

12. Nickelson (1990, p. 303). 
ordinated way. The NHK production standard was apparently designed to provide fairly easy transitions into a variety of transmission standards. In particular, the number of active lines, 1,035, was a compromise, chosen because it is a relatively low-denominator fractional multiple of 483, the number of active lines in NTSC, and of 575, the number of active lines in PAL and in SECAM. This choice would make it easier to use HDTV programming for NTSC or PAL/SECAM broadcasts. It also would be consistent numerically with the optimal and most likely choices in the United States and in Europe for the number of active lines in HDTV transmission standards-if HiVision were rejected and Europe and this country went their own ways on transmission standards. ${ }^{13}$ Yet this compromise may prove a strategic mistake.

In 1986 the Japanese government asked the CCIR to adopt NHK's production standard-sometimes known as the 1,125/60 standard (1,125 total lines, 60 frames per second) - as an international standard. In an echo of the color TV story, although with Japan rather than the United States in the pioneer's role, European delegates, especially the French, blocked acceptance. (The CCIR traditionally requires consensus before adopting a recommendation.) Although various reasons have been cited, most commentators believe that protectionism was at the heart of this refusal. Subsequently, the Eureka-95 project, a joint venture under the auspices of (and with funding from) the European Community, was formed to develop a European HDTV. ${ }^{14}$

In the United States the Advanced Television Systems Committee, a private industry group, recommended to the State Department in 1986 that the NHK 1,125/60 technology be adopted as a world production standard. In the CCIR the U.S. State Department typically follows the recommendations of respectable industry groups such as the ATSC and, in particular, the American National Standards Institute (ANSI). The State Department followed the ATSC's recommendation at the 1986 CCIR meeting, and ANSI adopted 1,125/60 (slightly modified) as a standard. But in 1989, shortly before another CCIR meeting, NBC proposed a 1,050/60 production standard, and the consensus of U.S. interests on 1,125/60 began to unravel. Capital Cities/ABC successfully

13. Johnson (1990, p. 9).

14. On the color TV story see Crane (1979). On Eureka 95 see Patrick Samuel, "HighDefinition Television: A Major Stake for Europe,' Rice (1990, chap. 3). 
appealed to ANSI to reverse its adoption of $1,125 / 60$, claiming that the adoption was inappropriate since the link between production and transmission standards was important and since there was little enthusiasm for adoption of the HiVision transmission standard in the United States. Detecting a lack of consensus, ANSI withdrew 1,125/60's designation as a standard.

Since the 1989 CCIR meeting, efforts have continued to try to set a world production standard. Disagreement has crystallized over the choice of the frame rate - that is, the number of frames per second (fps). NTSC has $60 \mathrm{fps}$, while PAL and SECAM have 50. NHK chose 60, which maximizes compatibility with NTSC; of course, $60 \mathrm{fps}$ yields a somewhat steadier picture than does $50 \mathrm{fps}$. NHK demonstrated a converter that will produce $50 \mathrm{fps}$ from a 60 -fps tape, but the Europeans still felt that adoption of $1,125 / 60$ would disadvantage them. The standard of 80 fps was proposed, but generated little enthusiasm-perhaps vindicating the European contention that the frame rate is important. In May 1990 the Plenary Session of the CCIR again rejected SMPTE 240M, a version of the NHK $1,125 / 60$ production standard.

Although a world production standard has not been reached, many significant parameters have been standardized at the CCIR. The fewer parameters that differ among competing standards, the easier and cheaper it is to translate or convert programming material among them. This should help world trade in programming, although it will not be as seamless as if a full production standard had been agreed upon.

\section{Developments in Europe}

The European HDTV joint venture Eureka 95 was formed in 1986, with EC funding of $\$ 180$ million and with the participation of Philips, Thomson, Bosch, and others. Much more has been spent or committed since then. Philips and Thomson plan to spend $\$ 3.8$ billion by $1995 .{ }^{15}$ The goal was to develop a "European" HDTV; this could mean anything from paying more attention to compatibility with PAL and SECAM, to sheer protectionism (in the dubious hope that designing a different standard would effectively exclude Japanese manufacturers).

Since PAL/SECAM has 575 active lines, the most convenient HDTV

15. Peter Fletcher, “Gathering Steam,"' Electronics 63 (October 1990):48-51. 
standard for Europe should have twice as many, or 1,150 active lines, to facilitate conversion. The NHK 1,125/60 proposal (or its SMPTE modification), with 1,035 active lines, is a compromise, and it is distinctly imperfect if only Europe is being considered. This providesdepending on one's point of view-either a genuine reason or a pretext for European rejection of $1,125 / 60$. The Eureka project has therefore developed a 1,250-line system, HD-MAC, with 1,150 active lines, designed for DBS broadcast. ${ }^{16}$ Like PAL and SECAM but unlike NTSC and $\mathrm{HiVision}$, HD-MAC has a 50 -fps frame rate that facilitates conversion between it and PAL/SECAM. HD-MAC is not receivercompatible with PAL and SECAM, so Eureka has also developed transitional systems, D-MAC and D2-MAC. These are receiver-compatible with PAL and SECAM. In other words, existing receivers can produce a picture from D-MAC/D2-MAC broadcasts, and HD-MAC will be compatible with D-MAC and D2-MAC.

Having underwritten development of the MAC family of standards, the EC has strongly encouraged satellite broadcasters to adopt D2-MAC. At first the EC proposed a strong line, tentatively announcing that all new satellite services after January 1993 were required to use MAC, and large new receivers had to be MAC-capable. Later these provisions were softened. ${ }^{17}$ Taking a subsidy approach rather than a legislative one, the EC has allocated a large, though conflictingly reported, sum of money to help pay broadcasters' costs of converting to D2-MAC. ${ }^{18}$ Despite this, satellite broadcasters have been resisting. Many apparently prefer to stick to PAL, or to use PAL Plus, an EDTV system. They state that D-MAC/D2-MAC is little better than PAL, that the required receivers are expensive, and that $\mathrm{HD}-\mathrm{MAC}$ will be outmoded before it is introduced since it is an analog system. ${ }^{19}$ The centralized development of the MAC family may be stymied by the availability of an EDTV

16. Wassiczek, Waters, and Wood (1990) state that HD-MAC picture quality is "equivalent to"' 1,150 active lines (p. 320). Confusingly, they also mention 1,152 lines (p. 316).

17. “M. Alain Prestat devient PDG de Thomson Consumer Electronics,', Le Monde, January 12-13, 1992, p. 15.

18. “'High-Definition Europe TV,' New York Times, November 21, 1991, p. D19; and "High-Definition Tunnel Vision,', The Economist, vol. 321, November 9, 1991, pp. 17-18. The subsidy to broadcasters is reported in The Economist as a billion ecus $(\$ 1.25$ billion).

19. Grindley (1992). According to The Economist, vol. 321, November 9, 1991, the receivers cost $\$ 6,200$. 
system and by the option to wait for a superior, all-digital system. The European Community's strategy to use D2-MAC to soften and thus encourage the transition to HD-MAC may well fail. ${ }^{20}$

\section{HDTV Development in the United States}

Because of the political clout of established broadcasting interests, HDTV will not displace terrestrial broadcasting in the United States as it will elsewhere in the world. This is unfortunate in terms of HDTV and in terms of rational use of scarce spectrum. What is more, broadcasters have delayed the whole process. The United States is far "behind"' Japan and even Europe. This delay, however, has had an unintended side result: the United States is likely to get a significantly better system than was available even a few years ago, at least if we take as given the self-imposed constraint of consistency with terrestrial broadcasting.

\section{Broadcasters}

In the United States, unlike in most other countries, broadcasting has traditionally been organized around local stations. These terrestrial broadcasters are increasingly facing actual and potential competition from other video delivery media. The first significant threat has come from cable television. Cable operators distribute local broadcast signals, but they also offer other programs that cut into the broadcasters' market. A far stronger threat than C-band satellites is direct broadcast satellites that can send signals to much smaller (napkin-sized) and much cheaper home satellite dishes. Another threat is lurking on the horizon: fiber optic networks to homes (or "to the curb") that could have enormous bandwidth.

HDTV worsened the fundamental threat already facing terrestrial broadcasters. When HDTV was mooted, broadcasters knew that their need to fit their signals into 6 megahertz of bandwidth per channel would put them at a severe disadvantage relative to other delivery media in bringing HDTV signals into the home. Worse yet from the local

20. One report suggests that the EC is on the verge of abandoning MAC altogether. See Jonathan B. Levine and Neil Gross, "HDTV: Europe May Already Be an Also-Ran," Business Week, January 13, 1992, p. 46. 
broadcasters' point of view, HDTV was likely to increase their costs considerably. A widely cited study estimated the cost of HDTV transmission equipment at $\$ 38$ million, considerably more than the roughly $\$ 25$ million median price for TV stations sold during the 1980 s! ${ }^{21}$ Local broadcasters cannot charge more for an improved service, unless they increase the number of ad minutes per hour, which might well backfire. The only benefit to the local broadcast industry as a whole from adoption of HDTV would come if viewers watched more television. They probably would but not by very much since on average each TV household in the United States already watches seven hours a day. Accordingly, the broadcasters' collective interest seemed to lie in rejecting HDTV. Indeed, they showed little interest in adopting the technology early on. To broadcasters as a group, HDTV was a threat, not a promise.

At the same time, if HDTV were available - that is, if a standard were set and receivers marketed - then it might well pay for an individual station to adopt HDTV since HDTV-equipped viewers would shift their viewing patterns in favor of an HDTV station. This effect would be slow for the first HDTV station in a city: few if any local viewers would have HDTV sets. In time, however, the demand shift might be significant, especially among the richest viewers (a most attractive target audience). Thus, if HDTV were available, there could arise a prisoners' dilemma structure among broadcasters: each individually might want to adopt HDTV, but as a group all might be worse off in the end than if the technology had never appeared.

Such a structure is not exceptional: in general terms, if an innovation reduces marginal costs more than it reduces average costs, it may be typical. Consider, for instance, a differentiated-good duopoly model with firms located at the ends of the unit interval. Suppose that marginal costs are independent of output and are initially at level $c_{0}$, and all buyers are served in equilibrium at prices $k+c_{0}$; each firm's profits are $k / 2$. Now suppose that an innovation becomes available that reduces marginal costs to $c$, but it involves a small fixed adoption cost, $F$. Then

21. See the "Ross study" released in 1989 by the Advisory Committee Systems Working Party 3. More recent cost estimates are $\$ 10$ to $\$ 12$ million for the first stations to adopt and about half of that for those who wait a few years-perhaps only $\$ 1$ million to pass through a network signal. See "New HDTV Estimates: \$12 Million or Less,' Broadcasting, October 29, 1990, p. 33; "HDTV: Coming 'Sooner Than Expected',', Broadcasting, October 15, 1990, pp. 43-47; and TV Digest, May 13, 1991, p. 9. 
it is a dominant strategy (provided $F$ is sufficiently small) for each firm to adopt the innovation, but joint profits fall by $2 F$.

In most industries, firms can do little about this problem: once the technology exists, it is hard to collude to prevent its adoption. In broadcasting, however, the firms could do just that: they could discourage the FCC from moving quickly to set standards for HDTV, so no standard would be set, at least for a while; and they could claim that the already developed technology was unsuitable (thus delaying any implementation). This, according to some reports, they did. The broadcasters' Advanced Television Systems Committee was formed almost two years after NHK's demonstration of HDTV technology at the annual conference of the Society of Motion Picture and Television Engineers (SMPTE). The committee did not form a study group on HDTV until $1987 .{ }^{22}$

But broadcast television could not ignore competition from other distribution technologies, particularly cable. Cable operators, unlike "free"' local broadcasters, can charge more for higher quality TV. The cable industry could therefore be expected to be more enthusiastic about adopting HDTV, especially given the preponderance of movies and sports programming on cable, material thought to be especially well suited to HDTV. Likewise, HDTV had appeal for DBS-based pay TV. And if cable or DBS adopted HDTV, broadcasters would find it hard to play catch-up. Cable and DBS, because they face much less severe spectrum/bandwidth constraints than do broadcasters, would naturally choose a relatively uncompressed system such as HiVision; once consumers began buying HiVision sets, broadcasters would have a tough time displacing a standard that was already becoming established in the market.

This possible threat meant that the broadcasters had to remain alert so that they could urge the FCC to set a terrestrial-broadcast HDTV standard that would help them join any HDTV bandwagon. The prospect of being a little late probably would not have greatly concerned them because the market would surely wait for so important a segment as terrestrial broadcasters - if it was apparent that the broadcasters were in the process of adopting. And, in turn, the prospect of such a response

22. "Clear Advantages to High Resolution,"' Broadcasting, vol. 100, February 16, 1981, p. 30; and "ATSC to Look into High-Definition Broadcasting,"' Broadcasting, vol. 112, March 16, 1987, p. 61. 
may have deterred cable operators from adopting HiVision themselves. They must have feared that the FCC would have been stung into action, doubtless interfering with market adoption of their putative system.

Thus, the broadcasters did not want HDTV to happen and refrained from actions that would make it more likely to happen. At the same time, they watched to make sure that no competing medium was about to adopt HDTV. If such an adoption appeared imminent, they would petition the FCC to set an HDTV standard that would be consistent with terrestrial broadcasting. Although they could not expect that process to be completed before the rival medium was able to adopt, they could hope and expect that the market would not adopt a standard incompatible with terrestrial broadcasting if a broadcast-compatible standard were thought to be on its way. The prospect of such a reaction, in turn, would prevent any costly moves toward adoption by rival media.

This was quite a clever strategy, but it was undermined by another development: competition for spectrum at the FCC. Responding to the great commercial success of cellular telephones, the FCC announced that it was considering reallocating to cellular service some unused parts of television's ultrahigh frequency (UHF) band. If the broadcasters waited too long, they might lack the additional spectrum that they would need to join an HDTV bandwagon. Moreover, if the process of reallocating UHF spectrum went too far, rival media could adopt HDTV without the threat of a "wait-for-us" move by broadcasters.

In 1987, perhaps as a result of these developments, the Association of Maximum Service Telecasters and other broadcaster groups asked the FCC to act on HDTV. The FCC announced a freeze on reallocations of spectrum. ${ }^{23}$ It formed an Advisory Committee on Advanced Television Service to study possible transmission standards-with a strong emphasis on terrestrial broadcast standards, despite the spectrum considerations ${ }^{24}$ In other words, the FCC was not asking, " How can HDTV

23. "Inquiry Begun on Development and Uses of Advanced TV Systems; Immediate Freeze on TV Allotments Imposed,' FCC press release, July 16, 1987.

24. See Federal Register, 52, October 16, 1987, pp. 38523-24. The FCC Advisory Committee is playing a central role in selecting an HDTV standard. The Advisory Committee includes selected cable operators, networks, studios, set manufacturers, and broadcasters, as well as representatives from the State Department, the Commerce Department, the National Association of Broadcasters, and the National Cable Television Association. 
best be provided to American households?" but "How can HDTV be adapted for the existing broadcasting system?"

The FCC stated that it "would not retard" the development of HDTV via nonterrestrial media, but by actively developing a terrestrial HDTV standard, it made it hard for cable operators or a DBS entrant to choose a different standard. More precisely, such a move would fail if set manufacturers and consumers preferred to wait a couple of years to see what would happen at the FCC. The FCC's entry into the process greatly affected people's expectations of whether broadcasters would introduce an HDTV technology; with network externalities such expectations can matter a lot. ${ }^{25}$

And, with the threat of preemptive entry by a competing medium removed, the broadcasters again have every reason to delay. For instance, the testing process by the Advanced Television Testing Committee (ATTC) is costing approximately $\$ 15$ million. ${ }^{26}$ This is roughly the cost of a single station adopting HDTV or of ten thousand viewers buying HDTV sets (on a very optimistic estimate of prices). The ATTC is testing the six competing systems seriatim; testing each system will take about seven weeks. Presumably, at a cost of a few more millions, the systems could be tested simultaneously (or at least two at a time); the testing process might then take three months instead of more than a year. ${ }^{27}$ Were there a real sense of urgency about adoption, the test center's proponents would surely be willing to contribute the extra money. Recently, FCC Chairman Alfred Sikes "warned broadcasters urging delays in broadcast high-definition television deployment that UHF spectrum for HDTV cannot be held indefinitely.," 28

The FCC has ruled in broadcasters' favor at every turn, including

25. Katz and Shapiro (1985, 1992); and Farrell and Saloner (1986). One could view the FCC's entry as a preannouncement by broadcasters, as in Farrell and Saloner.

26. "Advanced Television Testing Begins: 1993 is Target for New 'HDTV' Standard," ATTC press release, July 12, 1991, p. 1.

27. FCC Advisory Committee on Advanced Television Service, Test Sequence and Calendar, revised June 7, 1991. Testing was scheduled to end June 15, 1992, but it has slipped about five months behind schedule, despite the withdrawal of one of the six systems to be tested. See Edmund L. Andrews, "Delays Seen in Testing HDTV Plans," New York Times, March 25, 1992, p. D4.

28. 'Sikes Reaffirms Preference for Simulcast HDTV,' Broadcasting, vol. 121, October 28, 1991, p. 27. 
the allocation of currently unused spectrum to existing broadcasters. In terms of how HDTV will be implemented, what matters is that the FCC is awarding spectrum to permit terrestrial broadcasting, and it is otherwise encouraging the use of that medium. From a political economy point of view, it is worth noting that existing broadcasters apparently will be the beneficiaries of this largesse. ${ }^{29}$ Although the FCC did decide not to retard adoption by alternative media, this decision had little effect given the FCC's announced intention of setting a standard consistent with terrestrial broadcasting.

Through its effects on market participants' expectations, the very existence of an HDTV standard-setting process at the FCC has effectively foreclosed satellite and cable operators from proposing a system unsuited to terrestrial broadcasting. Broadcasters are concerned about the cost of adopting HDTV transmission and studio equipment, estimated at $\$ 10$ to $\$ 12$ million for stations that adopt promptly. But each station faced with that choice will have been given a $6 \mathrm{MHz}$ incremental channel by the FCC. Thus, the broadcasters have forestalled an external competitive threat and at the same time gained for themselves very valuable spectrum space.

\section{Spectrum Issues and the FCC}

Although there is a limitless amount of electromagnetic spectrum, the part that is good for ground-to-ground transmission is, for technical reasons, severely limited. Rapidly growing technologies other than television, such as cellular telephone service, yearn for that spectrum. A major social cost of implementing HDTV through terrestrial broadcast is the use of scarce spectrum space. Basic economics tells us that scarce spectrum should be reserved for applications that (1) are highly valued and (2) cannot easily be offered without using such spectrum. Both television and telephone services can be provided by wire rather than over the air; in each case the largest advantages to transmitting information using the electromagnetic spectrum are mobility and any saving on the cost of wiring. HDTV may be of limited incremental value over NTSC, so it is unclear that it satisfies the first condition. As for the

29. Federal Register, 56, November 18, 1991, pp. 58207-14. See also Bob Davis, "'Back Channel: FCC to Grant Owner of Every TV Station Another License Free,' Wall Street Journal, March 18, 1992, p. 1. 
second condition, HDTV signals can easily be sent via cable or via satellite signals that do not use the crowded and valuable portion of the spectrum suitable for ground-to-ground transmissions. At the same time, cellular telephone is highly valued and does require ground-to-ground transmissions.

A new generation of television presents an opportunity to reconfigure use of the spectrum. It gives nations the opportunity to provide television service via satellite or via cable (either coaxial cable installed by the existing cable TV industry or fiberoptic cable proposed by telephone companies and others). Such a change would free up critical spectrum space for a number of alternative technologies for years to come.

NTSC color television broadcasts use $6 \mathrm{MHz}$ of bandwidth per channel, and they require "taboos" and vacant channels between active channels in order to minimize interference. A high-definition signal, transmitted according to similar protocols, would occupy approximately $30 \mathrm{MHz}$; this is sometimes described as the bandwidth of an "uncompressed" HDTV signal. This might make it seem impossible to fit HDTV within the existing television spectrum without displacing existing services, but this is not the case. Data'compression techniques have advanced greatly since the NTSC standard was set in 1953, and compression is much more effective on digital signals than on analog signals. Moreover, by reducing power requirements and in other ways, modern technology mitigates the problem of interference between adjacent channels; HDTV broadcasting should be able to use at least parts of the "taboo" channels. Finally, many UHF channels are vacant. Thus, even in the most crowded television broadcast markets, there is some spectrum to work with.

Spectrum, however, is not completely fungible. Existing channels cannot be moved around without making existing receivers obsolete. And, while it is technically feasible to construct a new channel out of noncontiguous scraps, many experts believe that doing so inevitably compromises quality and creates technical problems. Existing channels operate at widely varying powers and therefore occupy different but overlapping geographic areas. Thus, the question of how much spectrum is available in which markets is very complex.

The FCC's Office of Engineering and Technology studied this problem and found that most existing stations could be allotted an additional 
$6 \mathrm{MHz}$ channel. ${ }^{30}$ The exact proportion varied considerably depending on the technical assumptions made (and, of course, the unfortunate exceptions would disproportionately be in the nation's largest markets). But allocating more than $6 \mathrm{MHz}$ would present grave problems, both in terms of total spectrum and in terms of repacking. Thus, the FCC tentatively decided that "systems requiring more than $6 \mathrm{MHz}$ to broadcast an incompatible signal, such as the MUSE $9 \mathrm{MHz}$ system, will not be authorized for terrestrial broadcast service." It also decided to consider "only those plans that would use $6 \mathrm{MHz}$ or less of additional bandwidth per station." 31 The FCC intends to give additional spectrum to existing broadcasters to use for HDTV, insofar as the overall allocation of spectrum to television (including the now unused channels) permits.

The Japanese and the Europeans are introducing HDTV via satellite. When enough of their citizens have HDTV (or, in the European case, the transitional D2-MAC) receivers, they can end terrestrial television broadcasts, thus liberating the television portion of the terrestrial transmission spectrum. The United States has decided to fit HDTV into the already crowded terrestrial television spectrum. Thus, the United States will have a heavily squeezed HDTV system (with the extra costs, compromised quality, and reduced scope for later enhancements that this implies). At the same time, less spectrum will be available for other uses. In the medium run the FCC apparently means to give each established broadcaster another $6 \mathrm{MHz}$ channel to use for HDTV. This will not directly take spectrum from other uses. It will, however, use spectrum that is not currently used and could otherwise be transferred to other uses. ${ }^{32}$ In the long run, probably after a lengthy transition period, currently scheduled to last to the year 2008, NTSC broadcasts can be phased out. Then the HDTV channels will presumably be locked up for television use (in contrast to the situation in Japan and Europe). Although the FCC is considering how and when to recapture the NTSC channels, we doubt that broadcasters will be forced to give up their NTSC channels as soon as NTSC broadcasts cease to be the most

30. FCC (1988, tables 1 and 2); modified in a separate report, December 1989.

31. FCC (1988, paragraphs 4 and 82).

32. Actually, the FCC proposes if necessary to rescind the licenses of some low-powered TV and nonprofit TV stations in order to provide HDTV channels to existing commercial broadcasters. See FCC Notice of Proposed Rulemaking, November 1991. 
socially valuable use of those channels. In short, we fear that the FCC's attachment to established broadcasters has led to some very unfortunate decisions regarding spectrum allocation.

\section{Other Major Decisions by the FCC}

The FCC decided to protect the installed base in the hands of consumers as well as to protect the existing broadcast industry. Specifically, it decided that the introduction of HDTV must not strand owners of existing sets. Either the HDTV system must be "receiver compatible", (that is, produce an NTSC-quality picture on an NTSC receiver), or a separate NTSC or receiver-compatible signal must be "simulcast" alongside NTSC for an unspecified period of time until NTSC can be abandoned. ${ }^{33}$

This decision was probably redundant since totally incompatible systems are very hard to get adopted; the CBS color standard is a classic example, as we will explain. Or it may simply be wise advice to a nascent HDTV industry. However, it may also prevent the adoption of incompatible systems that nevertheless can be viewed on an NTSC receiver equipped with a (perhaps inexpensive) "decoder." NHK's system has this property. ${ }^{34}$

Finally, the FCC appears to have been painfully aware of the AM stereo debacle in which the FCC announced a procedure to pick among the contending AM stereo technologies, followed the procedure, and then withdrew its designation after protests from some broadcasters, amid concern about possible litigation by losing proponents. Perhaps

33. See Synopsis of Notice of Proposed Rulemaking, 1991, Federal Register, 56, p. 58207. Another interpretation of this decision is that since the FCC means to allocate HDTV channels to existing stations, it must regard HDTV as an upgrade to NTSC rather than as a new service-otherwise its allocation plan for the additional spectrum might violate the Ashbacker doctrine. (The U.S. Supreme Court held in 1945 that to award a franchise to one applicant that makes it impossible to award a similar franchise to another without a comparative hearing violates the latter's rights.) For some discussion of this, and of the FCC's proposals for exactly what "simulcasting" should mean, see Broadcasting, October 28, 1991, p. 27.

34. In FCC (1988, para. 126 (3)) this issue is mentioned, but it does not seem to have had much impact. We do not know why. The ability to make an incompatible system compatible at a social cost below the reported retail price of $\$ 150$ should change the calculations about whether to perpetuate an inefficient use of spectrum in order to protect the installed base of sets. 
partly in response to this, the commission stated in September 1989 that it will indeed set a terrestrial HDTV standard, although it "will not retard" the adoption of HDTV by other media; it will not, as in AM stereo, say "let the market decide", and then let the market languish. ${ }^{35}$

The process for setting a standard is as follows. Proponents provided details and prototypes of their systems to the ATTC, a special-purpose, private, nonprofit testing body funded by industry contributions (predominantly from television networks) and by fees paid by system proponents. The ATTC is currently testing systems in a simulated-broadcast environment, complete with artificially produced interference (including an actual vacuum cleaner motor). CableLabs is undertaking parallel testing for cable transmission. These tests will measure objective aspects of system quality and will produce high-definition videotapes of the simulated reception of the various systems. Nonexpert viewers at the Advanced Television Evaluation Laboratory (ATEL) in Ottawa will then subjectively evaluate these videotapes.

After its tests are complete (in late 1992), the ATTC will report to the FCC's Advisory Committee, which will make a recommendation to the FCC, which will then choose a standard. Although the FCC is not bound to follow the Advisory Committee's recommendation, it would be surprising if, after setting up such a structure, it did not do so. The Advisory Committee is seeking information about costs as well as quality of the different systems, but this information is proving hard to gather since no equivalent of "testing" is practical. ${ }^{36}$ As a result, it seems to us that the structure is disposed to select the system that will yield the highest quality, subject to the bandwidth constraints imposed by the FCC. The FCC thus set up a development contest in which contestants tried to squeeze as good a signal as possible into a $6 \mathrm{MHz}$ additional channel.

To keep from stranding the installed base of NTSC receivers, the

35. Of course, the FCC seems to have had similar intentions in the case of AM stereo. See Besen and Johnson (1986). The FCC is carefully not doing the HDTV testing itself. The ATTC has asked sponsors for input on the fair design of the test process, and it has received signed statements accepting the fairness of the process. Edmund L. Andrews, "Six Systems in Search of Approval as HDTV Moves to the Testing Lab," New York Times, August 18, 1991, p. F7.

36. Conversation with Laurence J. Thorpe, the chairman of Systems Subcommittee Working Party 3 (Economic Assessment), February 1992. See also that subcommittee's Fourth Report, January 1992, pp. 6-7. 
HDTV standard must be receiver compatible or else NTSC broadcasts must be "simulcast" alongside HDTV broadcasts during a probably long transition period. Because receiver-compatible or " augmentation", systems use the NTSC signal rather than discard it and start over, they would make more efficient use of spectrum in the short run. But they lock in the NTSC signal. A "simulcast" system may enable the United States to abandon NTSC broadcasts and reclaim the spectrum eventually. For this reason, and also because allocating even 3 additional $\mathrm{MHz}$ of contiguous spectrum is more problematic than allocating 6 additional $\mathrm{MHz}$ of noncontiguous spectrum (augmentation channels preferably should be contiguous), the FCC has decided to use a simulcast approach. ${ }^{37}$

\section{Proposed HDTV Systems}

The history of the contest so far is striking mainly in that most proponents dropped out or merged with one another before testing began. When the FCC issued its "Tentative Decision and Further Notice of Inquiry' in September 1988, there were 23 proposals. The list shrank to six before the fall of 1991 when testing began. The six still in contention were NHK's Narrow-MUSE; "Spectrum-Compatible', SCHDTV from Zenith and AT\&T; DigiCipher and the ATVA Progressive System from the American Television Alliance (General Instrument and MIT); and the Advanced Television Research Consortium's ACTV and ADTV (the consortium consists of North American Philips, Sarnoff Research Labs, NBC, and Thomson). ACTV has since been withdrawn.

Because of the spectrum constraints imposed by the FCC's attachment to terrestrial broadcasting (and broadcasters), the key problem facing would-be developers of a U.S. HDTV standard is signal compression. An impressive variety of compression algorithms has been proposed. For example, Osborne (now withdrawn from the contest) developed an augmentation system in which an HDTV receiver takes the NTSC signal and interpolates from it to form a tentative high-definition picture. (This is roughly what many improved-definition television (IDTV) systems, already available in stores, do.) The augmentation channel is then used primarily to correct interpolation errors (measured in the studio by comparing the true high-definition picture with the picture as down-

37. Federal Register, 55, September 26, 1990, p. 39275. 
graded to NTSC and then interpolated back up). Another set of compression techniques depends on the fact that the human eye (other than Ted Williams's) does not readily perceive much detail or color in a moving image. Yet another strategy is to exploit the fact that the typical picture on television is almost identical to the frame before. Only a modest amount of "change" information usually needs to be sent, but occasionally there is a sudden shift! When many pixels do change, it is often because the camera is panning, and some systems have economical ways to transmit this panning information. All of this conserves spectrum, but it imposes severe computing requirements on receivers and studio equipment alike. Proprietary compression techniques are also prospectively a source of considerable financial return for system developers. ${ }^{38}$

For some time Zenith was the main contender that was wholly American. Sarnoff had some European partners, and General Instrument and MIT were seemingly not taken seriously. Zenith then sold its computer business, almost as if to say to the FCC, "Pick our standard or risk losing the last American TV manufacturer.' Until June 1990, the closing date for entries in the FCC-ATTC sweepstakes for HDTV, Zenith apparently believed that its system was as good as any other and that it would win because of the nationality issue.

Meanwhile, many experts had suggested that it might be the wrong time to pick an HDTV standard. In the then-current state of technology, it would have to be at least partially an analog standard, and if the United States waited a decade it should be possible to design an alldigital system. On the last day for entries, however, General Instrument entered its system - and, to the surprise of almost all industry observers, it was an all-digital system. All the remaining proponents except NHK then developed all-digital systems within a year.

\section{EDTV: A Threat?}

In Japan, where HDTV is already being broadcast, some observers think that its success is threatened by ClearVision, an EDTV system. In Europe many believe that MAC is doomed because broadcasters

38. See "High Definition Television: The World at War," The Economist, vol. 316, August 4, 1990, p. 59. 
prefer to use EDTV such as PAL + and to wait for an all-digital system to become available. Recall that EDTV requires only modest changes in the broadcast signal and does not degrade-indeed, sometimes improves-reception in existing receivers.

Is EDTV also a threat to HDTV in the United States? First, Faroudja's SuperNTSC reportedly produces a much improved picture at very modest cost: an incremental cost for receivers of about $\$ 300$ and for broadcasters of about $\$ 300,000$ (roughly 10 and 30 times less than the corresponding numbers for HDTV). SuperNTSC withdrew from the FCC process after the FCC stated that it was looking for a true HDTV system, not (initially) EDTV. ${ }^{39}$ Yves Faroudja has stated that his incremental improvements probably do not require FCC approval and can simply be implemented; indeed, there have already been test broadcasts. ${ }^{40}$

The early rejection of EDTV by the FCC exemplifies a bias toward high-quality, high-cost solutions, or "gold plating." As we explain later, we expect another layer of gold plating in the choice among HDTV systems because the testing process is better able to judge quality than to compare expected future manufacturing costs.

\section{Technology Choice}

The United States has taken a very different approach to HDTV technology selection than has either Japan or Europe. Japan picked HiVision at a very early stage, subsidized its (and apparently only its) development, and promoted it heavily. The Europeans adopted a similar approach. They chose the MAC standard relatively early and supported it through Eureka. This highly centralized approach forgoes the benefits of competition in research and development (including both incentive effects and diversification advantages) in order to avoid duplication of effort and to gain planning economies from an early knowledge of what system will be put in place. The U.S. process, by contrast, is encouraging intersystem rivalry at least until 1993, when the FCC plans to

39. Federal Register, 55, September 26, 1990, p. 39275.

40. Robert D. Hof, “Poor Man's HDTV?’ Business Week, June 24, 1991, pp. 10810. 
pick a standard, and potentially after that if nonterrestrial systems pick a different standard. This approach involves delay (which has certain advantages with rapidly advancing technology) and some inevitable duplication of effort. ${ }^{41}$ The U.S. approach also harnesses competitive forces and offers some social diversification. It remains to be seen how the fully centralized approach will perform relative to the semicentralized approach being taken in the United States. As of this writing, decentralization is looking good.

Of course, HDTV is seriously flawed even as a single data point in such an ambitious comparative systems question. For instance, the different jurisdictions are choosing at significantly different times, and the fact that the United States is likely to end up with a system that is technically superior to HiVision and MAC cannot be entirely credited to the virtues of competition. We must also credit the effluxion of time. Still, had the FCC pursued a Japanese- or European-style approach, General Instrument would surely not have been the developer chosen, and all-digital HDTV would perhaps still be seen as a decade away. Among the benefits of a decentralized system is the opportunity for even rank outsiders to prove their stuff.

We turn now from our political-economic narrative to discuss some issues in economic theory that arise directly out of the technologychoice process in HDTV, especially as it is being undertaken in the United States. We organize this discussion around the decision problem facing a public authority such as the FCC.

\section{The General Problem}

Choosing a standard for HDTV transmission is an example of the general problem of choice among competing technologies. In many markets this is not a public policy problem: it is optimal to let the market choose and quite possible to have many technologies persist side by side. But when compatibility and network externalities are

41. Duplicative expenditures have not been enormous, at least by the standards of the numbers bandied in the industrial policy debate on HDTV. U.S. proponents' development costs as of 1990 appeared to range from $\$ 2$ million to $\$ 100$ million. See Bob McMahon, “'HDTV: Worth all the Fuss?' San Francisco Examiner, April 29, 1990, p. D1; and Dwight B. Davis, "U.S. Struggles for HDTV Agenda," Electronic Business, August 20, 1990, p. 39. 
significant, it may be wise to have a central authority pick a single technology. The FCC's view - with which we are inclined to agreeis that this is the case with HDTV.

Consider then the following general setting. Several incompatible technologies are under development or potentially under development. All are designed to serve the same demand. Each technology can be improved through additional development efforts, although improvement is stochastic. Once a system is introduced commercially, it becomes much harder to improve since equipment, once sold, embodies the technology in place as of the system's date of introduction. Ultimately, only one technology can survive; if several are introduced and compete, some consumers will be left with equipment that is incompatible with the winning system.

We will focus on the case in which, as in the U.S. process, competing systems are developed privately for profit. The central authority (which we will often refer to as the "FCC' for short) has decided to choose a 'winner' in some administrative fashion before any sales to market participants begin, and it can within limits determine the structure of rewards to the winner and perhaps to others.

What legal or institutional systems perform well in this setting? Performance involves at least the following considerations: entry and exit of contestants in the development competition (that is, the number of technologies pursued throughout the development process, possibly based on the progress achieved by each); the date at which a new technology is commercialized; the choice of which technology is introduced; and the speed and extent of diffusion of the selected technology. We will examine those aspects of the problem that seem most relevant for HDTV.

\section{Market Intervention: Pros and Cons}

Economists naturally begin by asking whether any centralized intervention in technology choice is warranted. Why not rely fully on the market to pick a technology? If the FCC decided to rely solely on the market in the case of HDTV, it might sell or give away spectrum space, allow spectrum to be traded, and let the owners of the spectrum decide on the format of the signals they transmit, so long as they do not interfere with others' signals. This is close to the FCC's approach in the case 
of AM stereo radio. ${ }^{42}$ The commission, however, has explicitly rejected market reliance for HDTV. We can still briefly consider the pros and cons of such an approach.

A fully market-driven process might operate roughly as follows. Sponsors would compete to develop HDTV systems. At any time a sponsor could choose to introduce its system - that is, make its HDTV receivers (and transmission equipment) commercially available. In response, sponsors of rival systems might introduce their systems, either immediately or with a lag. Any HDTV sponsor commercializing its technology would choose the price for its receivers (and transmission equipment). The sponsor also might put into place a licensing policy. For example, it might make its technology available to others at a specified royalty rate. A low royalty rate might help promote the system, especially if the sponsor were committed to such licensing for an extended period of time. ${ }^{43}$ For example, to enhance market adoption, RCA voluntarily shared a great deal of NTSC technology for some years after the NTSC color standard was picked. ${ }^{44}$ Vertical integration strategies may also help. RCA's subsidiary, NBC, was for many years the main provider of prime-time color programming, and the purchases of Columbia by Sony and of MCA by Matsushita may have been intended in part to guarantee the availability of some HDTV programming.

Leaving the choice of a technology standard to the market surely has advantages. The market can judge quality after development has been completed, and it can get a firm indication of cost. Bright ideas from unexpected sources such as General Instrument may be able to thrive better than under an administrative approach. Finally, the bandwagon competition will likely keep prices low (perhaps even below cost) early on, plausibly helping to establish a viable network.

All the same, many of the common reasons for presuming that market equilibria are efficient do not apply to technology choice problems, especially those with network externalities. For example, there is little reason to expect market forces to yield a socially desirable portfolio of development projects as system sponsors decide whether to enter or

42. Besen and Johnson (1986).

43. The value of such commitment is analogous to that studied under the rubric of second sourcing. See Shepard (1987); and Farrell and Gallini (1988).

44. Levy (1981). 
exit from the development competition (and how hard to work). There is no reason to expect that market forces will cause a new generation of products to be introduced at the optimal time. ${ }^{45}$ Nor should we expect the ex post market diffusion of the chosen technology to be optimal. Reliance on the market may lead to a prolonged period of confusion or uncertainty during which multiple systems compete and many consumers wait until they think they can see who will win the market bandwagon contest. Market competition also may leave some consumers-the bold ones-stranded with abandoned, incompatible equipment. In general, the market may not solve efficiently the coordination problems involved in picking a standard. In addition, the natural monopoly aspect of technology standards may lead to ex post market power and resulting inefficiencies that may be severe when network externalities are important, as we discuss later.

Although it is sometimes appropriate to rely on market forces to select technology standards, thoughtful intervention may be advisable. In the case of HDTV, the FCC is managing the transition to HDTV, and we focus on how such centralized management should be done. At the same time, we would like to take the edge off the traditional distinction between fully decentralized market processes and centralized choice. In many industries where standards are important, the "market" process includes an explicitly cooperative phase during which industry members meet and agree on voluntary industry standards. And, on the other hand, with HDTV the FCC is relying heavily on an industrybased Advisory Committee to recommend a standard, as it did with previous generations of television.

\section{The Problem Facing a Standard-Setting Authority}

Given competing technologies that are stochastically improving, what policies should a central authority establish to influence the research and development competition, the timing of adoption, the choice of

45. This point is well known in the context of patent races. With embodied technological progress, each developer realizes that early introduction has preemption value but that it may undermine success if the system is not advanced enough to attract consumer demand or to fend off later, superior alternatives. See Katz and Shapiro (1992) for an analysis of market biases in the timing of new product introduction in a model with network externalities, although their model has only one potential entrant. 
technology, and the diffusion of the technology? First, we will address the question in terms of ex post concerns. Given several choices for a standard at a given time, but limited information about those choices, how do alternative procedures perform in selecting a standard? We then address ex ante concerns. What methods for choosing a system will have desirable properties in terms of entry and exit choices by developers and the timing of technology introduction, as well as the ultimate diffusion of that technology?

\section{Technology Choice Rules: Ex Post Concerns}

In this section we postpone assessing the effects of different rules (on sponsors' participation decisions, for example) and consider only what selection rules are likely to perform well given the options and the information available when a choice is made. We address the tradeoffs that arise when a technically superior system is more expensive than an inferior system or when two systems differ in more than one aspect of quality (for example, when one system provides a better picture for viewers in the central service area, while another provides a better picture for viewers near the fringe of the reception area). We find that the traditional prescription for socially optimal quality choicechoose according to the average buyer's willingness to pay for qualitymust be modified when network externalities are important; marginal buyers' preferences should also count since it is their choices that determine the size of the network and thus the extent of network externalities. The buyers are households considering buying HDTV receivers, and the network externalities come from provision of programming and transmission choices.

First we assume, unrealistically, that the FCC has a great deal of information on the costs and qualities of the various systems, as well as on demand and consumer benefits. Then we ask how the FCC should choose a system when it has incomplete information. Of course, if the FCC's information, although incomplete, is as good as anyone's, then this is simply a matter of choice under uncertainty. But if the FCC knows less about certain aspects of the competing systems than do the systems' proponents, a more interesting problem arises.

The ATTC, CableLabs, and the ATEL are likely to give the FCC as 
good information as is available about the technical quality of the competing systems. But the Advisory Committee's attempts to learn about the costs (to consumers, to broadcasters, and to other participants) of the competing systems are less well organized and may produce less reliable information. Given that the information is less reliable, it seems rational to give it less weight. There is, however, an alternative: use incentive mechanisms to induce proponents to reveal their private information about costs. We investigate this possibility.

Specifically, we pose the following question: Given a number of candidate HDTV systems differing in quality and cost, and given that quality is observed by both the FCC and sponsors but cost is observed only by a system's sponsor, how do various selection procedures perform in picking the system offering the highest net benefits from HDTV? In principle, the presence of private information need not lead to inefficient choice: a Groves-style modification of the Loeb-Magat mechanism yields the first-best outcome. ${ }^{46}$ Extant and proposed choice mechanisms, however, bear little resemblance to such a mechanism. Later we will discuss auction mechanisms, which have been proposed by some critics of the FCC's selection policy. ${ }^{47}$ The merits of auctions cannot be assessed without evaluating the FCC's intellectual property policy. We explain how the two interact.

\section{Quality Choice with Complete Information}

In this subsection we ask the following question: If the FCC has full information on the competing systems, how should it trade off quality and cost when picking a new technology subject to network externalities?

A Static Model. Let consumers be indexed by their willingness to pay for HDTV, above and beyond NTSC. The willingness to pay for an HDTV set by consumer $z$ is given by $v(z, q, x)$. Define the index $z$ so that $v_{z}<0$; a higher index thus denotes a lower willingness to pay for HDTV. The quality of a system is denoted by $q$, and the total number of buyers (that is, the network size) is $x$. For convenience, we define the willingness to pay by the marginal buyer as $p(x, q) \equiv v(x, q, x)$.

46. Loeb and Magat (1979).

47. See, for example, Donlan (1991). 
The cost of manufacturing sets to quality $q$, above and beyond the cost of a NTSC set, is given by $c(q)$. Consumer $z$ 's net willingness to pay for quality is $v_{q}(z, q, x)-c^{\prime}(q)$.

Assuming that sets are available at cost (that is, that sets are supplied perfectly competitively), the total number of sets that will be purchased if quality $q$ is selected is given implicitly by

$$
v(x, q, x)=c(q),
$$

which can also be written as $p(x, q)=c(q)$. Total welfare (gross consumer benefits less production costs) is

$$
W(q)=\int_{0}^{x}[v(z, q, x)-c(q)] d z
$$

where $x$ depends on $q$ as given implicitly by equation 1 .

We imagine that a number of systems might be available, representing different points on the quality-cost tradeoff, $c(q)$. To learn which of these systems is best to select, we can see how welfare varies with $q$, accounting for the higher costs that go along with systems of higher quality. To find the optimal quality, differentiate $W$ with respect to $q$ to obtain

$$
W^{\prime}(q)=\int_{0}^{x}\left[v_{q}(z, q, x)-c^{\prime}(q)\right] d z+\frac{d x}{d q} \int_{0}^{x} v_{x}(z, q, x) d z
$$

The first term in equation 2 is aggregate net willingness to pay for quality, given network size $x$. The second term reflects the effect on benefits of an adjustment in network size because of the quality change. Recall that network size is not optimally set; indeed, the network size is too small from a social perspective because of the positive externalities generated when an individual joins the network (buys a set).

Equation 2 can be expressed in terms of several intuitive economic measures of benefit. Call the elasticity of demand for sets $\epsilon$-that is, the price elasticity corresponding to the inverse demand curve $p(x, q)$. Define the average net willingness to pay for quality as

$$
A \equiv \frac{1}{x} \int_{0}^{x}\left[v_{q}(z, q, x)-c^{\prime}(q)\right] d z
$$

and the marginal net willingness to pay for quality as 


$$
M \equiv v_{q}(x, q, x)-c^{\prime}(q) .
$$

Finally, define the "externality ratio" as

$$
E \equiv \frac{\int_{0}^{x} v_{x}(z, q, x) d z}{v(x, q, x)},
$$

the ratio of external benefits to private benefits for the marginal participant on the network (marginal buyer of a set). With these definitions, it is not hard to show that the quality of sets conforming to a socially optimal product standard must satisfy the following equation:

$$
A+M E \epsilon=0 .
$$

If the marginal buyer places the same marginal value on quality as does the average buyer, then the rule for choosing the optimal quality is simple: set the net willingness to pay of the marginal buyer and average buyer equal to zero. More generally, however, optimal quality choice involves a tradeoff between the interests of the average consumer and those of the marginal consumer; optimality requires that the average and marginal buyers' net willingness to pay are of opposite signs.

If there are no network externalities, $E=0$, then quality should be chosen to set average net willingness to pay to zero. (Remember that net willingness to pay accounts for production costs.) With network externalities, however, some weight should be given to the marginal buyer's willingness to pay, $M$. The greater the elasticity of demand for sets and the greater the externality ratio, the more weight should be given to the marginal buyer. ${ }^{48}$

Take the realistic case in which the marginal buyer is less willing to pay for quality than is the average buyer: $M<A$. Then equation 3 requires that $A>0$ and $M<0$. In other words, quality should not be pushed up to the point where the extra production cost equals the average buyer's willingness to pay for extra quality. The greater is elasticity of demand or the network externalities, the greater is the shortfall between optimal quality and the quality sought by the average user. In the case of HDTV, this reinforces our fear that an excessively costly system may be chosen. The Advisory Committee is likely to try to trade off

48. A monopolist would be exclusively concerned about the willingness to pay of the marginal buyer. 
quality versus cost based on the perceived preferences of an average user. (As we discuss elsewhere, it also is likely to fall into a goldplating trap even by that standard.)

This model especially begs to be placed in a dynamic framework: since, in a (continuous-time) dynamic adoption model, to paraphrase Andy Warhol, everyone is marginal for 15 minutes, interpreting results such as equation 3 is difficult. We therefore formulate a dynamic model of adoption with network externalities.

A Dynamic Model. Denote consumer $z$ 's flow benefit (in excess of NTSC flows) by $v(z, q, x)$ if network size is $x .{ }^{49}$ Again consumers are indexed by $z$ with $v_{z}<0$. Again define the willingness to pay by the marginal buyer as $p(x, q) \equiv v(x, q, x)$. The total flow benefits are

$$
B(x, q)=\int_{0}^{x} v(z, q, x) d z .
$$

The incremental unit cost (in comparison with NTSC) of manufacturing an HDTV set under the system with quality $q$, at date $t$, is $c(q, t)$, where $c_{t}<0$.

Write $x(q, t)$ for the number of people who have bought a set by date $t$; the number of people actually buying at date $t$ is $x_{t}(q, t)$. Each consumer has perfect foresight regarding HDTV receiver prices, which equal manufacturing costs at each point in time. Consumers also can foresee the evolution of network size, $x(q, t)$.

From the consumer's point of view, buying a set earlier requires an earlier outlay of the set cost, $c(q, t)$, and means forgoing any subsequent declines in prices. Consumer $z$, taking as given the growth of the installed base of HDTV receivers, $x(q, t)$, chooses a purchase date $t$ to maximize

$$
\int_{t}^{\infty} v[z, q, x(q, s)] e^{-r s} d s-c(q, t) e^{-r t}
$$

49. Our model makes the simplifying assumption that network externalities at any time are determined by the size of the installed base at that time. This assumption will fail if, as is likely, broadcasters and program suppliers look ahead and predict consumers' adoption decisions (or, for that matter, if there is a lag in their response). We also abstract from issues involving the gradual depreciation of existing NTSC sets. In other words, we ignore this fact: the day one's NTSC color set breaks down is a likely day for one to go buy an HDTV set. 
It is not hard to show that consumer $z$ 's optimal purchase date $t$ satisfies

$$
v[z, q, x(q, t)]=r c(q, t)-c_{t}(q, t) .
$$

We assume that the righthand side of this expression declines with time. Then the consumer's optimum is unique since $x$ can only rise over time. The fulfilled-expectations network evolution path $x(q, t)$ is thus given implicitly by

$$
v(x, q, x)=r c(q, t)-c_{t}(q, t) .
$$

Total welfare is

$$
W=\int_{0}^{\infty} B(x, q) e^{-r t} d t-\int_{0}^{\infty} x_{t}(q, t) c(q, t) e^{-r t} d t
$$

The final term in equation 6 measures the total cost of producing HDTV receivers. Integrating it by parts, we see that total costs are

$$
\int_{0}^{\infty} x(q, t)\left[r c(q, t)-c_{t}(q, t)\right] e^{-r t} d t .
$$

(Think of each consumer with an HDTV set at date $t$ as incurring a " "user cost" $r c(q, t)-c_{t}(q, t)$ at date $t$, regardless of when the consumer bought the set. ${ }^{50}$ ) Substituting this term into equation 6 , and substituting also for $B(x, q)$ using equation 4 , we have

$$
W=\int_{0}^{\infty}\left[\int_{0}^{x} v(z, q, x) d z\right] e^{-r t} d t-\int_{0}^{\infty} x\left(r c-c_{t}\right) e^{-r t} d t .
$$

Differentiating with respect to $q$ to find the optimal quality choice, we obtain

$$
\begin{aligned}
W_{q}=\int_{0}^{\infty}\left[\int _ { 0 } ^ { x } \left(v_{q}\right.\right. & \left.\left.+v_{x} x_{q}\right) d z\right] e^{-r t} d t+\int_{0}^{\infty} x_{q} v(x, q, x) e^{-r t} d t \\
& -\int_{0}^{\infty} x_{q}\left(r c-c_{t}\right) e^{-r t} d t-\int_{0}^{\infty} x\left(r c_{q}-c_{q t}\right) e^{-r t} d t .
\end{aligned}
$$

Happily, the middle two of these four integrals cancel since equation

50. Integration by parts confirms that adding up these flow user costs beginning at date $s$ gives a discounted total of $c(q, s)$. 
5 tells us that $v(x, q, x)=r c-c_{t}$. Noting this, and slightly rewriting, we get

$$
\begin{array}{r}
W_{q}=\int_{0}^{\infty}\left[\int_{0}^{x} v_{q}(z, q, x) d z\right] e^{-r t} d t-\int_{0}^{\infty} x\left(r c_{q}-c_{q t}\right) e^{-r t} d t \\
+\int_{0}^{\infty} x_{q}\left[\int_{0}^{x} v_{x}(z, q, x) d z\right] e^{-r t} d t
\end{array}
$$

The first two terms in equation 7 would be present without network externalities (in other words, even with $v_{x}=0$ ). The integrand in the first integral measures the extra benefits at each point in time that will be enjoyed if quality is higher. The second term measures the extra cost of providing higher quality; $r c_{q}+c_{q t}$ is the increment to each user's flow cost at date $t$ on account of a higher quality.

The first two terms in 7 describe the basic cost and benefits of selecting higher quality when consumers are gradually adopting a technology. In principle, equation 7 -in conjunction with demand information, $v(z, q, x)$, and cost information, $c(q, t)$-can inform the choice between, say, a system that is relatively unambitious technically and thus inexpensive and an ambitious system that is much more expensive early on but only marginally more expensive once the technology matures.

The final term in 7 captures the network externality effects. Without network externalities, we would have $v_{x}=0$ and this term would vanish. At each point in time, this term measures the effect of quality on network size, $x_{q}$, multiplies this by the total benefits of a larger network, $\Gamma(x)$ $\equiv \int_{0}^{x} v_{x} d z$, and then discounts.

Note that the effect of higher quality on network size, $x_{q}$, may be positive at some dates and negative at other dates. Recall that $x(q, t)$ is the equilibrium network evolution function, accounting for the higher cost of higher quality. From the definition of $x(q, t)$, equation 5 , we can see that $x_{q}(q, t)>0$ if and only if $v_{q}(x, q, x)>r c_{q}-c_{q t}$. An increase in quality will increase the installed base at date $t$ if and only if the net willingness to pay for quality among those actually buying (adopting) at date $t$ exceeds the increment in user cost at date $t$ on account of the higher quality. Since by assumption users can differ in their valuations of quality, and since quality and network size (a proxy 
for programming supply) may interact, this tradeoff could go different ways at different dates.

A costly increase in quality will augment network benefits if on average the quality increase raises network size at times when such increases are most valuable - that is, at times when many people are on the network or when those on the network highly value the addition of new users. ${ }^{51}$

IMPLICATIONS FOR THE FCC. The FCC should lean toward picking a system that will accelerate adoption at those dates when network externalities are most sensitive to total network size (that is, when $\Gamma(x)$ is large). Since the network externalities are generated through the supply of programming, the key issue is this: at what point in time will more rapid adoption stimulate a greater supply of programming - the production of material in HDTV format, the conversion of material into HDTV format, and, most important, the delivery of HDTV signals to the home?

The FCC should thus favor a system that appeals to customers who will be marginal buyers of HDTV sets at the time when broadcasters and programmers are considering hopping on the HDTV bandwagon. Industry commentators believe that this time will probably be two to five years after the FCC chooses a standard. It would thus seem desirable not to cater to the "vidiots," those video-hungry consumers who will be the first to adopt HDTV, even when programming is in very short supply. Nor would it seem desirable to cater to the laggards in an attempt to accelerate or achieve universal HDTV service. Once substantially all programming is produced and distributed in HDTV format, there are no further network externalities generated by additional consumer adoption. This suggests to us that it would be wise to evaluate a system's cost after several years of production experience. Indeed, the Advisory Committee's Working Party 4 has proposed that costs to consumers be assessed (as best they can be predicted) after five years of production. ${ }^{52}$

Our analysis can readily be adapted to give the ingredients necessary

51. If we make the reasonable (albeit perhaps optimistic) assumption that eventually all households will adopt HDTV, then $\lim _{t \rightarrow x} x(q, t)=X$ for all $q$, where $X$ is the total population size. In this case, using $x(q, 0)=0$, we must have $\int_{0}^{x} x_{t} d t=\mathrm{X}$, and hence $\int_{0}^{x} x_{q t} d t=0$. The final term in equation 7 is thus of the form $\int_{0}^{x} x_{q} \Gamma(x) e^{-r t} d t$, where $\int_{0}^{\infty} x_{q t} d t=0$.

52. Document SS/WP4-0079, November 5, 1991. 
to trade off one dimension of quality (for example, signal clarity for the household at the median distance from the transmission facility) against another dimension of quality (for example, total size of viewing area). The marginal benefits of each quality dimension, including network externality effects, can be compared with costs, and thus to each other, or the model could be changed in minor ways to make the comparison a direct one.

\section{Mechanism Design Meets the FCC}

Our analysis so far has assumed that system costs and quality are directly observable by the FCC. That seems unlikely to be true, especially for costs. System proponents (developers) may well know more than is readily observable. Can a standard selection process be designed to provide incentives that enable such private information to affect the final decision? In this section we illustrate that possibility with a mechanism-design approach for our technology selection problem. Our point is not the details of a mechanism that (in an inevitably oversimplified model) works in this respect; rather, it is that such information can potentially be elicited, and the FCC should evaluate its choice procedure from this perspective among others.

One Groves-style mechanism that works is as follows: let each system $i$ make a claim (that is, an announcement) regarding its unobservable manufacturing cost function, $c_{i}\left(x_{i}\right)$. The FCC then picks the system that will produce the greatest net benefits, $\max _{x_{i}} B\left(q_{i}, x_{i}\right)-c_{i}\left(x_{i}\right)$, assuming that the true cost equals the announced cost and that receivers are made available to consumers so as to maximize net benefits given that cost function. Here $B(q, x)$ is the gross benefit function and $x_{i}$ is the quantity of sets that will be sold if system $i$ is selected. The net benefits from choosing system $i$ are $W\left(q_{i}, c_{i}\right)=B\left(q_{i}, x_{i}\right)-c_{i}\left(x_{i}\right)$. If the second-place system in terms of net benefits is system $j$, then the winning firm receives from the FCC as a payment $B\left(q_{i}, x_{i}\right)-$ $W\left(q_{j}, c_{j}\right)$, and it is required to supply $x_{i}^{*}$ sets without further compensation; the sets will then be distributed. (In practice, the price should be allowed to adjust so that sales are $x_{i}^{*}$.) Losing firms are charged no fees and paid no money.

It is simple to check that (a) it does not pay to misrepresent one's cost function and (b) the best system is chosen and the optimal quantity 
of sets is supplied. This is simply an example of the "externality" payment principle as in the Groves mechanism. ${ }^{53}$ If system $i$ is chosen, the sponsor of system $i$ gets the benefits but must pay for the forgone benefits from choosing the next-best system, $j$. The winning firm is given the full amount of the benefits it generates, but it must bear its own production costs. Development costs are assumed to be sunk at this stage of the game, and therefore they play no part here.

We are not proposing this approach as a practical solution for the FCC. Obviously, although the mechanism addresses the issue of private information about costs, it requires knowledge about demand conditions (the benefit function), and it would not work if the sponsor played any role in promoting set demand, or if the sponsor (for efficiency) continued to work on the technology after it is chosen. The mechanism we describe also operates at a deficit.

\section{Simple Ex Post Rules for Technology Choice}

Our "optimal mechanism" showed that private information problems can sometimes be resolved through appropriate incentive structures. We now consider more realistic technology choice procedures that might elicit private information: auction mechanisms. A variety of possible mechanisms might be termed "auctions." In particular, it is often suggested that franchise auctions should take the form of a binding promise of a low price to consumers and that the lowest price should win. Such auctions often run into serious problems, especially if costs are very uncertain, if the "franchise" must be long term, and if quality differences are potentially important. ${ }^{54}$ Here we assume instead that proponents make no promises about prices (except as required by a reasonable-royalty policy, which we will discuss). Proponents would simply offer money in return for being chosen as the HDTV standard. The proponent who offered the most money would win.

An Auction Mechanism. An auction mechanism has attractive features. Obviously, it would be a handy source of government revenues, and it might displace some distortionary taxation (now or in the future). It also would have some direct efficiency effects. Other things being

53. Loeb and Magat (1979).

54. Williamson (1976). 
equal, a proponent whose system is cheaper or technically superior could expect to earn greater profits if chosen and therefore would be willing to bid more. The mechanism will tend to pick the cheapest or the best system, just as an auction of a painting tends to put the painting into the hands of the buyer who values it the most. Moreover, this is achieved without the need for formal comparisons on the part of the FCC. This need not mean a social saving on administrative costs since potential bidders must bear costs of preparing bids, but it may be helpful if the FCC is particularly slow or bad at assessing the costs and benefits of competing systems.

An auction mechanism also has disadvantages. First, since systems plausibly differ on many quality dimensions as well as on costs, the structure of cost and demand facing one system may have different properties (including demand elasticity) than that facing another. If so, the ratio of monopoly profits to consumer surplus may differ, and therefore the auction mechanism, which picks the most profitable system, may fail to pick the system with the highest total social surplus (profits plus consumer surplus). ${ }^{55}$ It is unclear to us how to model such problems for technology selection in general or for HDTV in particular, so we say no more along these lines.

Second, this form of auction will lead to monopoly pricing with resulting deadweight losses. Deadweight losses may be particularly high in markets where network externalities are important. Recall that deadweight loss stems from a monopolist's reduction in output below the competitive level. In a non-networks market, for each consumer who does not buy, society loses only the net value of that consumer's consumption-and when price is not far above marginal cost, that net value is small. In a networks market, however, there is an additional social loss: inframarginal consumers derive less value from their purchase because of the loss of the marginal consumer. Thus, for any given reduction in output below a competitive level, the social loss is more severe when network externalities are important.

We illustrate this point in figure 1 . The network size under marginalcost pricing is $x^{*}$, and $x_{m}$ is the network size under monopoly pricing. The demand curve $D D$ is $p=v(z, z)$; the willingness-to-pay curve given network size $x^{*}$, that is, $p=v\left(z, x^{*}\right)$, is $W W^{*}$; and the will-

55. For an analysis of auction mechanisms along these lines, see Borenstein (1988). 
Figure 1. Deadweight Loss from Output Reduction with Network Externalities Dollars

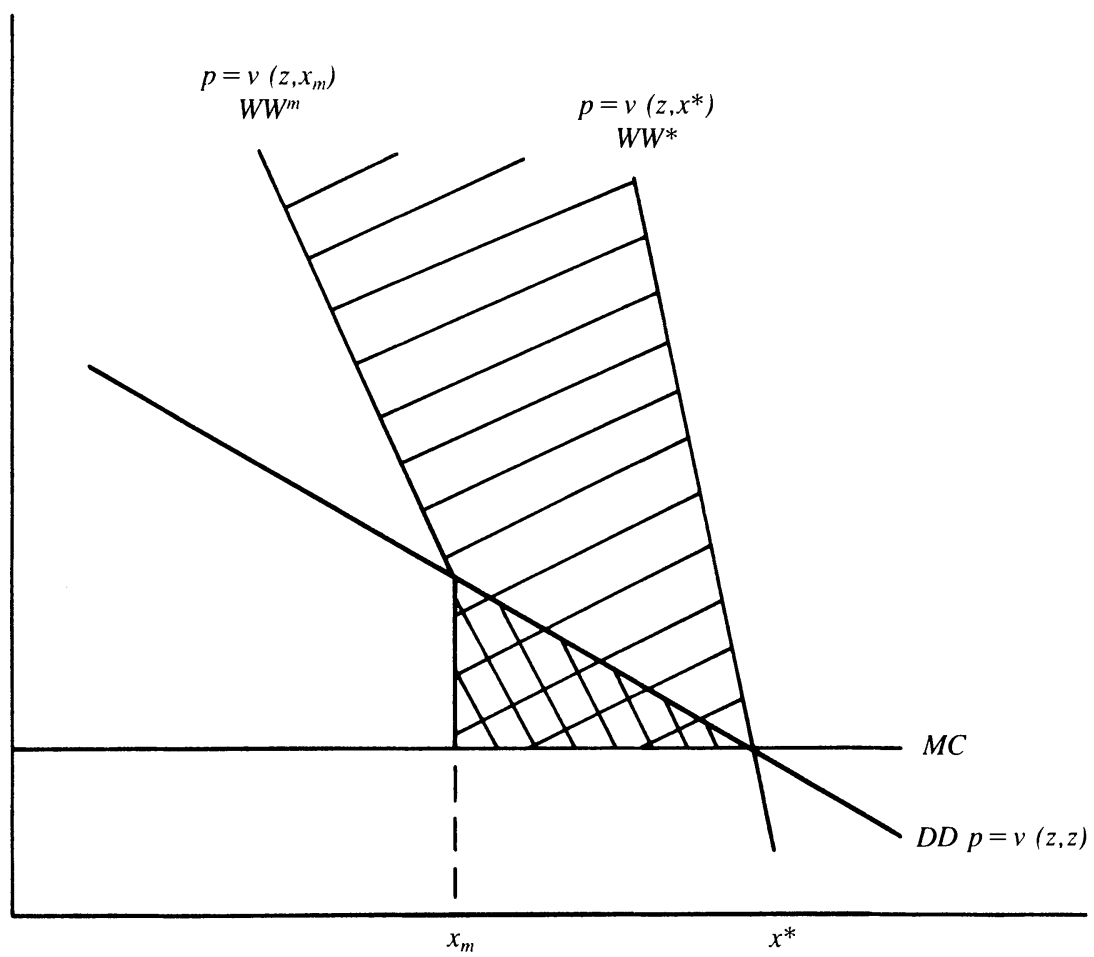

Output $z$

Source: Authors" calculations.

ingness-to-pay curve given network size $x_{m}$, that is, $p=v\left(z, x_{m}\right)$, is $W W^{m}$. The cross-hatched triangular region (bounded by $x_{m}$, the demand curve, and the marginal-cost curve, $M C$ ) is the standard monopoly deadweight loss caused by reducing output from $x^{*}$ to $x_{m}$. The lined region above the demand curve and between the two willingness-topay curves is the additional loss in the presence of network externalities.

Of course, a rational monopolist will take into account the fact that each consumer values the good more if he expects more people to buy, and so the reduction in output is not simply given. But as we now show in a simple special model, the deadweight loss from monopoly pricing is indeed a more severe problem the stronger the network externalities are. Suppose that consumer $z$ values the product at $v(z, x) \equiv 1+n x$ 
$-z$ if he believes that total sales will be $x$, where $z$ is uniformly distributed on an interval $[0, Z]$ for some large enough $Z$, and $n<1$ measures the importance of network externalities. Then the inverse demand curve facing the monopolist is $v(x, x)=p$, or $x=\frac{1}{Z} \frac{1-p}{1-n}$; if marginal production cost is zero, then profits are maximized at $p=p^{m}$ $=\frac{1}{2}$, with sales of $x=x^{m}=\frac{1}{2} \frac{1}{(1-n) Z}$. Total welfare, expressed as a fraction of welfare under the competitive solution $(p=0$ and $x=$ $\left.\frac{1}{(1-n) Z}\right)$, is $\frac{3-2 n}{4}$, which is decreasing in $n$, the importance of network externalities. ${ }^{56}$

We argue next that policies designed to deal with the deadweightloss problem can worsen this selection problem.

A Reasonable-Royalty Policy. Many formal standard-setting organizations try to avert deadweight losses from monopoly pricing by implementing a compulsory licensing policy. For example, the American National Standards Institute (ANSI) rules for accrediting standards require that any patented technology used in a proposed standard be licensed "without compensation" or "under reasonable terms and conditions that are demonstrably free of any unfair discrimination.", 57 The FCC does not have the legal authority to bind a system proponent to compulsory licensing, but the proponents now involved have agreed to a form of ANSI's patent policy, which requires open licensing at reasonable royalties. ${ }^{58}$ Moreover, the FCC has announced that it may consider proponents' licensing policies in picking a standard. ${ }^{59}$ What is "reasonable", is unclear, but industry sources suggest that royalties on HDTV sets might be $\$ 20$ per set; this is less than 1 percent of the likely retail price.

Such a policy will presumably reduce deadweight losses. Like any

56. This highly special model omits the dynamics of the adoption process. In some ranges adoption of HDTV by a consumer may reduce the benefits flowing to those who have not yet adopted, if the FCC's NTSC simulcasting requirement is not fully effective. Our model omits this possibility because it seems likely that the FCC will protect NTSCset owners from such stranding.

57. See Appendix I, “ANSI's Patent Policy,"' in ANSI (1987). Similarly, the directives of the International Standards Organization require that if a standard is prepared "in terms which include the use of a patented item,"' then the patent holder must promise to "negotiate licences under patent and like rights with applicants throughout the world on reasonable terms and conditions."

58. Harris (1992, pt. III.c).

59. See Federal Register, 56, November 18, 1991, p. 58212. 
policies that limit a patent holder's rapacity, however, it might also subvert the goal of intellectual property law: to reward with a degree of monopoly power the inventor of a socially useful product. Later we discuss whether a requirement of "reasonable royalties" unduly depresses the rewards to innovation; in the case of HDTV, the answer is probably no.

Another consequence of a reasonable-royalty policy is a little more subtle: it would weaken the ability of an auction mechanism to pick the best of a group of competing systems. Thus, it may significantly weaken an auction's efficiency appeal. A system's quality and cost are "higher powered" considerations when a winner is unrestrained by a compulsory licensing policy than when a winner is constrained; in the latter case such extraneous things as estimates of demand have a more dramatic effect on bidding behavior. We cannot expect the developers and proponents of HDTV systems, who will certainly be expert in HDTV technology, to also be expert in demand prediction. ${ }^{60}$ Estimates of consumers' willingness to pay for HDTV vary wildly. ${ }^{61}$ A proponent's optimism about the HDTV market may affect its bid as much as its knowledge about the quality and cost of its system. If so, allocation by auction will be a distinctly imperfect way of finding the optimal system.

We can illustrate this in a special case with linear demand: $x(q, p)$ $=\theta(q-p)$, where $q$ is the quality and $p$ the price of the system chosen; $\theta$ is a true demand parameter, not known in advance to anyone; and proponent $i$ gets a noisy signal of $\theta$ that leads him to act as if he had a firm estimate $\theta_{i}$ of $\theta .{ }^{62}$ Suppose that systems $i$ differ with respect to quality, $q_{i}$, and marginal cost, $c_{i}$. With an unrestricted monopoly, the expected profits of proponent $i$ are given by $\Pi_{i}=\frac{1}{4} \theta_{i}\left(q_{i}-c_{i}\right)^{2}$,

60. Of course, in bidding they will have an incentive to investigate demand as best they can and to buy market research firms' demand estimates, but they are likely to be uninformed consumers in a market for information-a notoriously tricky position.

61. We have been told that the FCC's Advisory Committee set up a structure to examine consumer demand for HDTV but abandoned the effort because, at $\$ 1$ million, it seemed too costly. For a summary of several influential and contradictory demand studies, see House Committee on Energy and Commerce (1989, pp. 576-83).

62. For simplicity we ignore some auction-theoretic subtleties. For example, a proponent's certainty equivalent for $\theta$, if one exists, will depend on the number of bidders because of the winner's curse. 
while actual welfare under monopoly if system $i$ wins the auction is $W_{i}=\frac{3}{8} \theta\left(q_{i}-c_{i}\right)^{2}$. Proponent $i$ will not be willing to bid up to $\Pi_{i}$, even in a second-price auction, because of the winner's curse. Nevertheless, the winner will be the proponent with the highest value of $\Pi_{i}$, or equivalently of $\frac{1}{2} \log \left(4 \Pi_{i}\right)=\frac{1}{2} \log \theta_{i}+\log \left(q_{i}-c_{i}\right)$. While variations in the $\theta_{i}$ confound the selection of the best system (the one with the highest value of $q_{i}-c_{i}$ ), the effect of such variations (measured logarithmically) is only half that of the socially informative variations in $q_{i}-c_{i}$.

Consider now the same auction but with reasonable royalties at a fixed rate $f$. Sales if system $i$ wins will be $x_{i}=\theta\left(q_{i}-c_{i}-f\right)$, and the winner's reward will be $f x_{i}$. Therefore, proponent $i$ expects a reward $\Pi_{i}=\theta_{i}\left(q-c_{i}-f\right) f$. Plausibly, $f$ is small compared with $q-c_{i}$, so we can approximate $\Pi_{i}$, by $f \theta_{i}\left(q_{i}-c_{i}\right)$. Thus, an auction with reasonable royalties picks the highest value of $\log \left(\Pi_{i} / f\right)=\log \theta_{i}+\log \left(q_{i}\right.$ $-c_{i}$ ). Variations in $\log \theta_{i}$ affect the auction as much as variations in $\log \left(q_{i}-c_{i}\right)$ and thus confound the selection of the best system twice as badly as they do without compulsory licensing.

In practice, the rewards to the winner of an auction under such an intellectual property policy are not limited to the royalties. Much of the winner's potential reward comes from the idiosyncratic cost advantage (or marketing advantage) that a winner enjoys just because it developed the system. For example, not all the winner's intellectual property and knowledge about the system must be revealed or licensed to competitors in order (as the ANSI policies require) to enable them to produce to the standard ${ }^{63}$ Moreover, the winner may have an advantage in developing subsequent (compatible) enhancements to the standard. Finally, consumers may prefer (rationally or not) to buy from the technology's original developer. These rewards may be rather weakly correlated with the social quality $q_{i}-c_{i}$ of the winner's system, thus introducing more noise into the process by which an auction mechanism picks out the best system. Moreover, these "noisy" components of the winner's reward are not reduced by a reasonable-royalty policy, whereas

63. In color television, RCA licensed a great deal of color-related technology at first in order to get the technology established, but after a few years it announced that it would no longer do so. This did not stop others from continuing to manufacture color sets and equipment, but it did exert RCA's competitive advantage as the developer of the technology. See Levy (1981). 
"reasonable"' licensing profits are likely to be much less than the monopoly profits available without licensing requirements. As a result, this noise is relatively more important under a reasonable-royalty rule.

We have argued that a policy of "reasonable royalties" may seriously weaken an auction's ability to pick the best system, when there are confounding variations in sponsors' demand estimates, access to capital markets, and so on. But a reasonable-royalty policy reduces deadweight loss from monopoly price distortions. This may be especially important in network markets. When, then, is such a policy desirable?

We ignore for now the possible effects on innovative effort and address the question in the following simple model. We assume that marginal costs are zero, and thus simplify variation in $\left(q_{i}, c_{i}\right)$ to variation in $q_{i}$, which we assume to be uniformly distributed on the interval $[0,1]$. Different proponents' values of $q_{i}$ are independent. We also assume that the consumers of type $z$ value the good at $q_{i}-z+n x$ if they see or expect a network of size $x$, where $z$ is uniformly distributed on an interval $[0, Z]$ for some sufficiently large $Z$. Thus, the ratio of monopoly welfare to competitive welfare for a given system is $(3-2 n) / 4$. In other words, for a given choice of system, a fraction $(1+2 n) / 4$ of potential total benefits is lost by allowing monopoly pricing. ${ }^{64}$ What is the countervailing loss from using a less effective selection system?

It would be interesting to explore in more detail the extent to which a reasonable-royalty rule weakens the auction's ability to pick the best system. Here, however, we take a simpler and starker approach: out of the $2 k$ competitors an auction picks the best system if there is no reasonable-royalty rule; it picks a random system if there is such a rule. ${ }^{65}$

The expected performance of the auction with a reasonable-royalty rule is better than that without such a rule, if and only if

$$
n>\frac{5 k-8}{6 k}
$$

or equivalently if

64. Total social benefits would be higher with an adoption subsidy than under competitive pricing because of the network externality. We realistically rule this out, however, and identify potential benefits with competitive benefits.

65. This is an extreme assumption for a purely illustrative model; the point is that the reasonable-royalty rule worsens the ability to pick the best system. 


$$
k<\frac{8}{5-6 n} \text {. }
$$

Note that for large values of $n$ (greater than 5/6), reasonable royalties are desirable for any number of contestants. For larger $n$ (network externalities are less important), deadweight losses become more important, making reasonable royalties more attractive. For small $n(n \approx$ 0 ), even for $k=2$, it is preferable to get the benefit of better system selection than to impose a reasonable-royalty policy so as to avoid deadweight losses from ex post monopoly.

\section{Cost Information and the FCC's Policy}

The FCC's actual policy is not an auction, and it certainly does not resemble the Groves mechanism. Relying on the ATTC, CableLabs, and ATEL, the FCC appears to be gauging systems' quality. It will combine this information with information on systems' cost and then try to identify the best system.

As the FCC probably realizes, its cost information is likely to be significantly less reliable than its quality information. Therefore, it may pick the system with the highest quality. ${ }^{66}$ Such a choice might be reasonable if the manufacturing cost of an HDTV television set is independent of the system chosen or if the costs are broadly uncorrelated with the quality. This seems unlikely, however, given the importance of electronic information-processing components in the cost of a set and given the different approaches taken by the rival systems in information processing and compression.

Without using some incentive scheme such as an auction, it is very difficult for the FCC to elicit cost information that the sponsors may have. Clearly, each sponsor has an incentive to claim that the cost of manufacturing a set according to its system is low. In public statements the sponsors have claimed low costs as a way of trumpeting the desirability and attractiveness of HDTV and of their systems in particular, but these claims have little credibility. ${ }^{67} \mathrm{We}$ are concerned that the

66. Because performance varies on many dimensions, the problem of picking the highest quality system is far from trivial.

67. Pressuring manufacturers to offer their sets at prices close to the prices they promised earlier might be unwise. With such implicit price controls, manufacturers' incentives to make quality improvements would be weakened. On problems with enforcing price promises, see Williamson (1976). 
current FCC policy will lead to very expensive HDTV. The FCC's relative inattention to cost considerations in the standard-setting process may retard the ultimate adoption of HDTV.

\section{Technology Choice Rules: Ex Ante Concerns}

We turn now to the far more complex problem of evaluating technology selection procedures from an ex ante perspective (that is, at the outset of a development competition). We are interested in the effect of technology selection procedures on developers' incentives to participate in the research and development competition and on the date of technology adoption.

\section{Participation Incentives for Sponsors}

We begin by asking how various ex post policies perform in giving sponsors appropriate incentives to enter or drop out of the development competition. To simplify the exposition, and without further loss of generality, suppose that we can define a goodness-of-system measure $v(c, q)$; the systems differ among themselves and over time in their values $v_{i}$, which stochastically increase over time as R\&D progress is made. The central authority, we assume, can identify the best system when it chooses one: that is, we set aside the information problems discussed above. Finally, we assume that each system's progress is independent of the presence or progress of others.

When the time comes to pick a system, what is the social benefit of sponsor $i$ 's participation in the competition? Call sponsor $i$ 's goodness $v_{i}$, and order the sponsors ex post so that $v_{1}>v_{2}>\ldots v_{n}$. The ex post social value of participation by all sponsors other than sponsor number 1 is zero. The social value of participation by sponsor 1 is the benefit from adopting a system with value $v_{1}$ instead of $v_{2}$.

This observation suggests some advantages of a winner-take-all prize system. In fact, there is one special benchmark case in which the sponsors' participation incentives are optimal. If total market demand is perfectly inelastic, and if Bertrand competition prevails ex post, then (absent any compulsory licensing) losing firms get nothing, reflecting their social contribution, and the winning firm's payoff exactly equals 
its social contribution $\left(v_{1}-v_{2}\right)$. In this very special case, since each firm's payoff equals its social contribution for all possible realizations of the $v_{i}$, firms' incentives to participate must be optimal. ${ }^{68}$

Now suppose, more realistically, that the winner's payoff is based on its proprietary cost advantage plus "reasonable" royalties charged to other manufacturers. Proprietary cost advantages come from a winner's familiarity with its system and from improvements it may have discovered that it need not license out (since they are not essential to conform to the standard). These cost advantages may be related to the winner's lead. A much superior system may also have considerable advantage based on trade secrets that can be withheld even after the basic system technology is made available to the public.

Other aspects of proprietary cost advantages, however, can easily constitute private rewards for which there is no corresponding social benefit. To take the extreme case, suppose that each proponent would get the same level of proprietary cost advantage. By choosing system $\mathrm{A}$ and thus giving proponent $\mathrm{A}$ a proprietary cost advantage, we make it impossible to do the same for system B; the size of A's cost advantage is thus socially irrelevant, but of course it is privately important for A's participation and effort choices.

What about royalty payments, the second major component of the winner's prize? It is unclear how far a winner's royalty rewards vary with the size of its winning margin. If royalty rates were truly fixed (say at a dollar or a percentage amount), the size of the lead would not affect the winner's royalties. But this may be too simple a view since it is unclear exactly what "reasonable" royalties are. For example, Stanley Besen of RAND has told us of a case where a standard-setting organization explicitly negotiated with the "winning" sponsor to lower the proposed royalties by threatening to change its choice of technology to the second-best one. Negotiations of this kind would indeed tie the winner's prize to its lead, but the organization in question was not the FCC, so we are cautious about drawing inferences for the HDTV process.

Broadly speaking, it seems to us that neither proprietary cost advantages nor royalty payments are likely to vary much with the winning

68. Demand must be inelastic for this system to achieve the first best because otherwise the second-best system does contribute to social welfare by providing pricing discipline for the winner. 
margin. Rewards are therefore probably excessive when the winning margin is small and inadequate when the winning margin is large. Although the test results are not yet publicly available, we suspect that the winning margin probably will be fairly small, and thus the winner's reward will be socially excessive. ${ }^{69}$ In this case reasonable (small) royalties appear reasonable indeed. Without such a policy the winner would enjoy substantial monopoly profits, which likely would exceed the incremental value of $v_{1}$ over $v_{2}$. This problem, in a slightly different guise (with speed rather than achieved quality as the measure of performance), is familiar from the theory of patent races: the winner earns a valuable monopoly, even if another developer performs almost as well (that is, would have achieved a comparable or perhaps identical discovery only a short time later).

Of course, the reward system should be judged from an ex ante viewpoint, not from the present, when the selection process is well along. It seems likely, however, that progress of the various systems has been highly correlated. Consider the remarkable progress in digitizing after GI's entry. This means that it would have been likely ex ante that the contest would be close.

The analytical framework of comparing the winner's private reward with the social value of the winner's presence becomes less helpful if losers also receive rewards that depend on their performance, or if losers make significant social contributions. In the HDTV case the latter is likely. General Instrument and NHK are two striking examples. General Instrument clearly has affected the outcome of the HDTV process, whether or not it wins, because its presence has pushed others to develop all-digital systems. If GI does not win, this will have been an important but largely unrewarded contribution. Similarly, NHK made the whole HDTV issue a live one in the 1980s. As a result of NHK's actions, American and perhaps European households will have access to HDTV earlier than they would have otherwise, yet it seems likely that NHK will receive no explicit rewards for this. ${ }^{70}$

69. In an auction system the winner's prize is more responsive to the winner's lead. The mechanism is most obvious in a second-bid auction, but it would apply under other auction rules also.

70. Of course, Japanese set manufacturers may reap rewards, and it can be argued that the Japanese government internalized these considerations in originally supporting HiVision. 


\section{The Timing of Adoption}

We turn now to another aspect of the technology adoption problem. Ignoring for the present any ex ante effects, and considering the problem as an optimal choice problem, we can ask when the authority should select an HDTV format for adoption. The question of when to pick a system is a complex stopping-rule problem when competing incompatible technologies are evolving stochastically. We do not seek to solve the optimal stopping-rule problem in general. Instead, we comment on the performance of several simple technology selection rules that an authority might employ.

We assume here that the central authority can observe each system's quality at each point in time and that any cost differences across systems are either small or are observable and factored into the measure of quality. Assuming that the prospective progress of each system depends only on the current quality levels of all the systems, the research and development process can be described by an autonomous stochastic system. We consider the following three rules. First, set a deadline and pick the best system at that date. This is the procedure being implemented by the FCC. (Note the caveat we mention later.) Second, pick a system as soon as one has a pre-specified clear lead ahead of others in terms of its quality and cost attributes. Third, pick the first system that achieves some threshold quality level.

Among these three rules (Deadline, Clear Lead, Threshold), the deadline rule is the only one calling for an adoption decision that is not solely a function of the quality progress of the various systems. The primary reason why a nonautonomous rule might be desirable is that the benefits of adoption may change over time in a way independent of the system qualities themselves. For example, if input prices such as electronic component costs or satellite transmission costs are falling over time, the benefits of adopting HDTV may rise with time for a given system quality. ${ }^{71}$

Absent such time-varying benefits, and supposing that system progress is exogenous, the optimal stopping rule must be a function solely of the achieved qualities. In general, the optimal rule consists of a

71. A decision rule based at least partially on conditions outside the control of the contestants reduces the sponsors' control over the process and may avoid some undesirable strategic effects. 
stopping region: those vectors of qualities for which adoption is optimal. Of course, the system with the highest quality should be adopted. (Any cost differences are incorporated into quality in this formulation.)

Neither Clear Lead nor Threshold is likely to be optimal. But we can see how these rules compare, especially depending upon the correlation between different systems' progress. Clear Lead will perform poorly if two or more systems are closely matched and attain a very high quality. Adoption of any of these systems will be highly desirable, but until one is sufficiently ahead, selection is delayed. If various systems' progress is highly correlated, this delay is likely to be long, and Clear Lead will perform rather poorly.

In contrast, Threshold calls for picking a system as soon as one attains a critical quality level, regardless of how close or far behind rival systems are. Waiting, however, will be more attractive if more systems are close to the leader since the expected progress of the lead system is greater in that case. If significant differences in the further progress of systems are likely, as when progress is not highly correlated across systems, Threshold would appear to perform rather poorly by ignoring the position of the second-ranked system. Threshold is approximately the rule implemented by an ordinary patent system: a technology can be marketed with legal protection once it achieves some novelty and "nonobviousness"' that is independent of the size of the leader's lead.

An interesting issue is the extent to which the ATTC or FCC can commit itself to a rigid testing or choice procedure. The response to the entry of General Instrument-presumably delayed to the last minute to prevent such a competitive response-is one example of the flexible attitude that has been adopted. Another related example concerns the timing of tests. As mentioned above, the ATTC is testing systems seriatim. Thus, to the extent that ongoing development is possible, those tested later can work longer on their systems and perhaps even respond to good or bad features revealed in earlier tests. Those who drew early slots have asked whether they can be retested at the end of the process if they make progress. The answer has been no, but apparently not a rigid no. ${ }^{72}$

72. See Federal Register, 55, September 26, 1990, p. 39276. 


\section{A Historical Comparison: Adoption of Color Television}

To better understand the process by which the United States is likely to adopt HDTV transmission and reception equipment, we have examined U.S. adoption of color television transmission and reception equipment. This historical comparison has several inherent limitations. The shift from black and white television to color television was arguably a more dramatic improvement in viewing quality than will be the shift from NTSC to high definition. The adoption of color television occurred 20 to 40 years ago when the television industry was far less significant than it is today. Cable television, home videocassette recorders, and satellite transmission-important factors in the television industry today - were not significant factors during the period of color adoption. Finally, the costs to stations and to households of adopting HDTV may not be comparable to the costs of adopting color television. Despite these limitations, we believe basic insights can be gained by examining the color television adoption process.

\section{Color Television Standard Setting}

The process by which a color television standard was chosen reveals the subtle interplay between standard setting by a central authority and a market bandwagon process. CBS and RCA (the owner of NBC) vied to set the new color standard. CBS had been urging the acceptance of its own color television system throughout the 1940s, and in October 1950 the FCC voted to adopt the CBS system as an industry standard. Unfortunately, the CBS system was incompatible with existing black and white signals: the black and white sets were unable to receive color broadcasts at all (even in black and white) without a special attachment. Furthermore, the CBS system was mechanical, at a time when many observers felt that an electronic system was both feasible and desirable.

Despite the FCC's endorsement of the CBS system, there was virtually no development of the color television industry using it. Partly this was because RCA remained critical of the CBS system, which was crippled by its incompatibility with black and white sets. Then in late 1953 the NTSC petitioned the FCC to authorize a compatible color standard. Before the year was over, the FCC reversed its earlier decision and adopted a compatible color system as the standard. Even CBS 
aligned itself with the NTSC compatible standard. No doubt the FCC's experience with color television was behind its decision to support a compatible approach to HDTV through simulcasting. Broadcasters and set manufacturers involved in the formal standard-setting process must also be careful to pick a standard that is acceptable to cable and satellite distributors. Otherwise, they run the risk of picking a standard that fails to generate a bandwagon behind it.

\section{The Timing of Color Television Adoption}

As we have noted, a television system has three major components: programming, distribution equipment, and reception equipment. In the case of color television, many broadcasters invested quite early in color capabilities even though little programming was available. Despite the leadership role played by many broadcasters, especially those affiliated with NBC and CBS, consumers did not purchase color television sets in great numbers until programming was quite widely available.

These trends and lags can be seen in summary information regarding the adoption of color television. Figure 2 shows the annual hours of color television programming supplied by each of the major networks from 1954 through 1965. In $1965 \mathrm{NBC}$, the leader in providing color programming, offered 4,000 hours in color, CBS 800, and ABC 600. More than a decade after a color standard was picked, two of the three networks still had rather limited color offerings.

Broadcasters, by contrast, moved quite rapidly to gain the ability to transmit color programs. ${ }^{73}$ Figure 3 shows the number of stations in the top 40 cities adopting color capabilities each year from 1954 through 1971. Of the 158 stations in our sample, 106 adopted color by $1957 .{ }^{74}$ In contrast to HDTV, where adoption of HDTV by broadcasters is likely to be a defensive measure, broadcasters saw significant benefits from

73. We report here on broadcasters' abilities ("network feed") to retransmit color programming supplied by a network or other programming source. This is distinct from, and in many cases significantly predated, a station's ability to produce its own color programming.

74. Our data on station adoption decisions are from issues of the Broadcasting Yearbook (Washington, D.C.: Broadcasting Publications). We restricted our attention to VHF stations in the top 40 cities, where city size was based on a 1970 measure of the number of homes in the "Area of Dominant Influence." ADIs are the standard measure of television markets. 
Figure 2. Annual Hours of Color Programming by Network, 1954-65

Color hours on NBC Color hours on CBS Color hours on ABC Hours

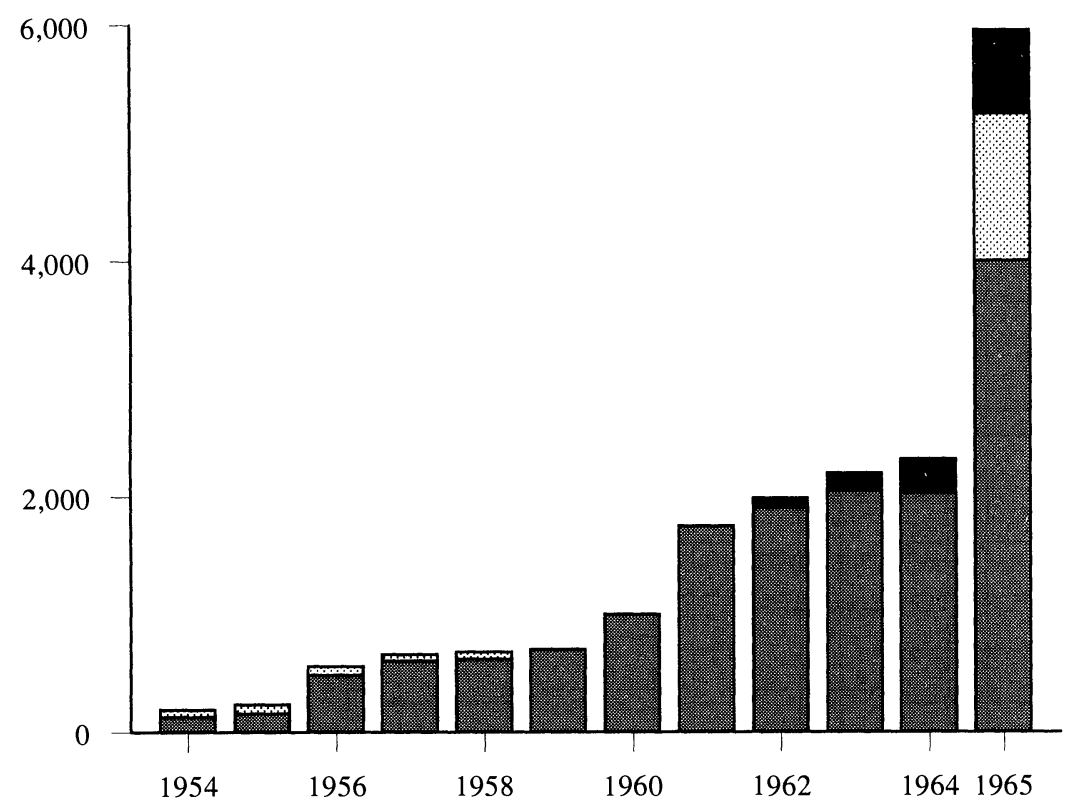

Source: Ducey and Fratrik (1989).

adopting color. During the 1950s, broadcasters recognized that color television would increase the amount of viewing and thus advertising revenues. In the 1990s it seems unlikely that HDTV will appreciably increase television viewing.

It is puzzling why so many stations adopted color when so little network color programming was available. We have observed that stations adopting color in 1954 experienced a much greater average increase in their advertising rates than did nonadopting stations. ${ }^{75}$ Adopting stations raised their advertising rates between 1953 and 1954 by an average of 29 percent compared with 12 percent for nonadopting stations. Virtually no color programming was available in 1954, and few

75. Advertising rates are measured using the station's list price for an advertiser to sponsor one hour of Class A programming time. Advertising data are from the Broadcasting Yearbook. 
Figure 3. Station Adoption of Color Television Capabilities, 1954-71

Number of stations

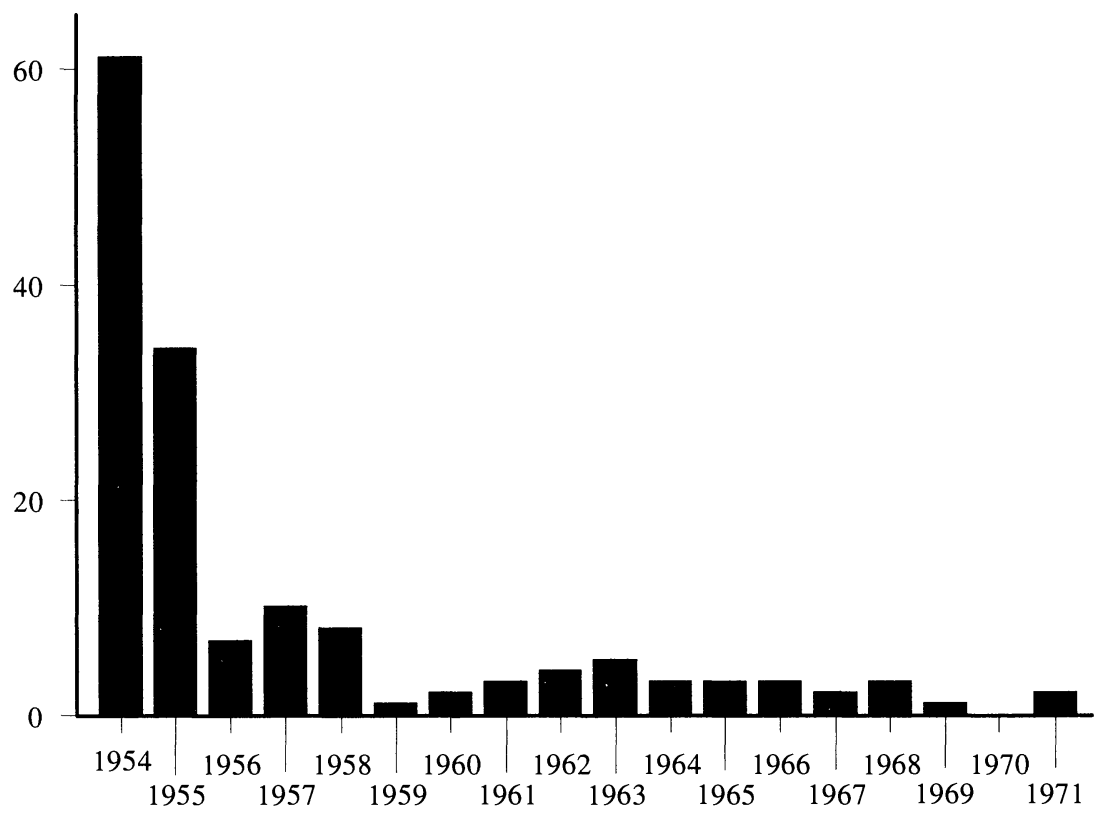

Source: See text, note 74 .

if any consumers bought color sets in that year. Therefore, we suspect that thriving stations chose to adopt color, not that color capabilities in 1954 had a significant impact on advertising rates.

As figures 4 and 5 reveal, the pattern of station adoptions was largely driven by network affiliation. ${ }^{76} \mathrm{NBC}$ and CBS affiliates adopted color very rapidly. $\mathrm{ABC}$ affiliates, independent commercial stations, and noncommercial stations adopted color much more slowly. ${ }^{77}$

To determine the role of network affiliation in determining when a station adopted color, we estimated a hazard rate model using data on

76. In constructing figures 4 and 5 we have had to deal with stations that changed their affiliation during the sample period and with stations listing multiple affiliations. In these figures we have counted a station according to its affiliation in the year it adopted color. For stations with multiple affiliations, we have counted that station as an adopting station for each network with which it was affiliated in the year of its adoption.

77. Adoptions recorded in 1972 in figure 5 actually represent stations that did not adopt at all during our 1954-71 sample period. 
Figure 4. NBC and CBS Affiliate Adoptions of Color Programming, 1954-61

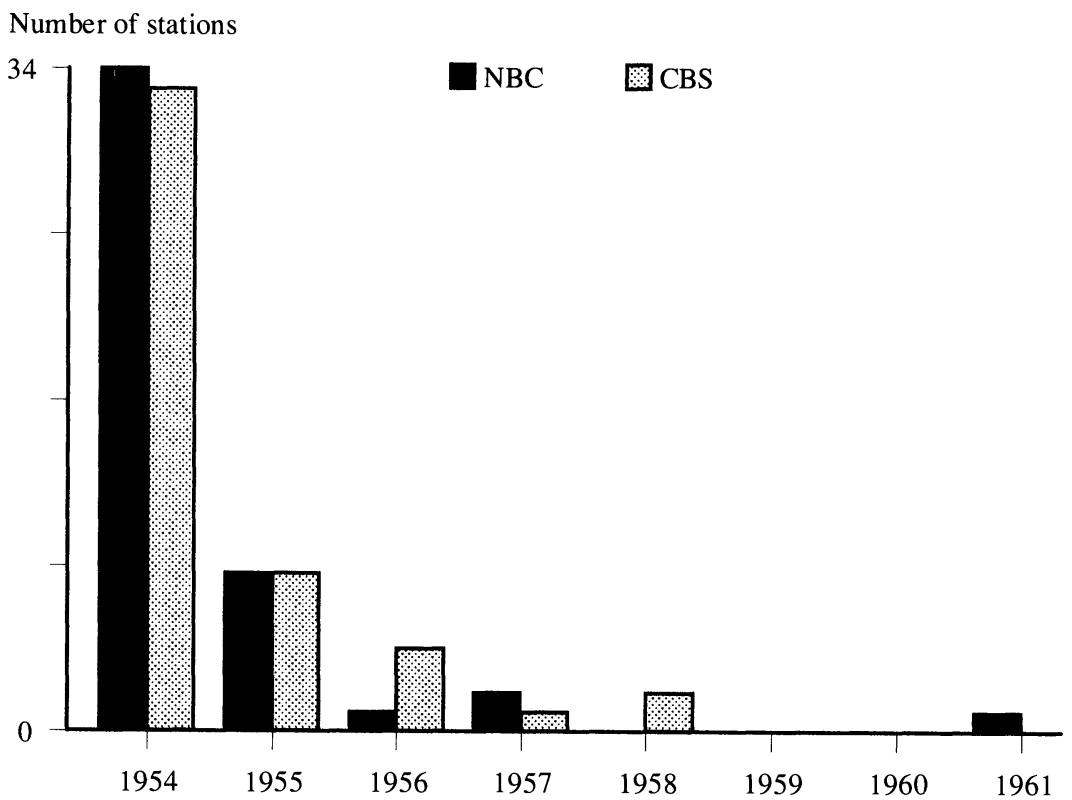

Source: Authors' calculations; see also text, note 76.

adoption dates and network affiliation. ${ }^{78} \mathrm{We}$ assumed a proportional hazard rate model, whereby the log of station $i$ 's hazard rate (probability of adopting color given that it has not yet done so) in year $t$ is of the form $h_{i}(t)=h(t)+b A_{i}$, where $b$ is a vector of coefficients to be estimated and $A_{i}$ is a vector of dummy variables that capture the network affiliation of station $i{ }^{79}$

NBC and CBS affiliates had essentially the same hazard rate each year. Stations with multiple affiliations experienced a hazard rate about two-thirds as large as that of NBC and CBS. The hazard rate of $\mathrm{ABC}$ affiliates was about one-sixth as large. For independent stations it was

78. For this purpose we restricted our attention to a subsample of our stations that were established by 1954 ; this involved 108 of our 158 stations.

79. We also explored the possibility that other factors, in particular the population served by the station, affected its likelihood of adopting color each year. A natural theory would suggest that stations in larger cities would be able to amortize the fixed cost of color capability over a larger audience, and should therefore adopt sooner. To our surprise we found that population was insignificant, and we omit it in the results reported here. 
Figure 5. ABC Affiliate, Independent, and PBS Adoptions of Color Programming, 1954-72

Number of stations

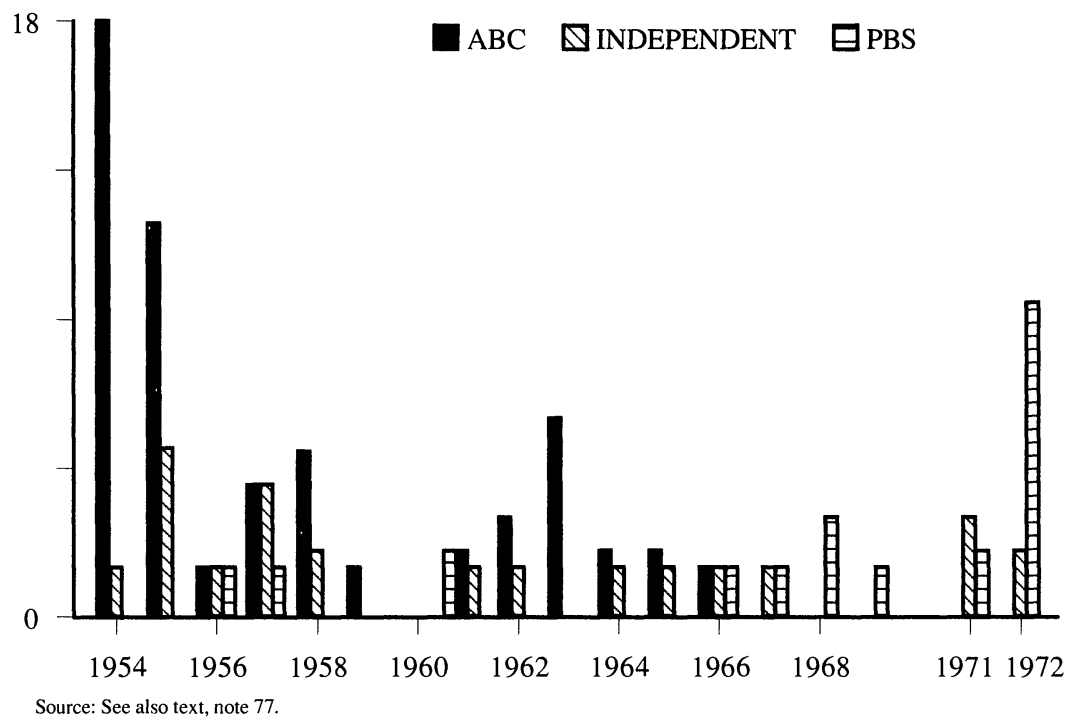

about one-tenth as large. Public stations showed a hazard rate about $1 / 100$ th of the NBC and CBS rate. ${ }^{80}$

Despite the relatively early adoption of color capabilities by broadcasters, consumers did not rush to buy color sets following the FCC's 1954 standard-setting action. Figure 6 reports the fraction of TV homes with color television sets annually from 1954 through 1990. As figure 6 shows, consumers did not buy color television sets in any significant numbers until the mid-1960s, at least a decade after many stations gained color capabilities. Figure 7, derived from figure 6, shows the hazard rate for television households for purchasing a color set (the probability that a household will buy color television in a year if it has

80. Although public stations clearly were the laggards, this last measure no doubt overestimates the noncommercial effect. In our sample of 108 stations established by 1954 , there were six noncommercial stations. Of these, one adopted color in 1968, one in 1970, and four had not done so by 1971 . We are concerned about the value of the data on color adoption by noncommercial stations. These stations had little incentive to report. The yearbooks were evidently used by advertising agents placing television ads, so commercial stations had every incentive to make sure that their color capabilities were fully reported. 
Figure 6. Color Television Set Penetration, 1954-90

Fraction of TV homes with color television

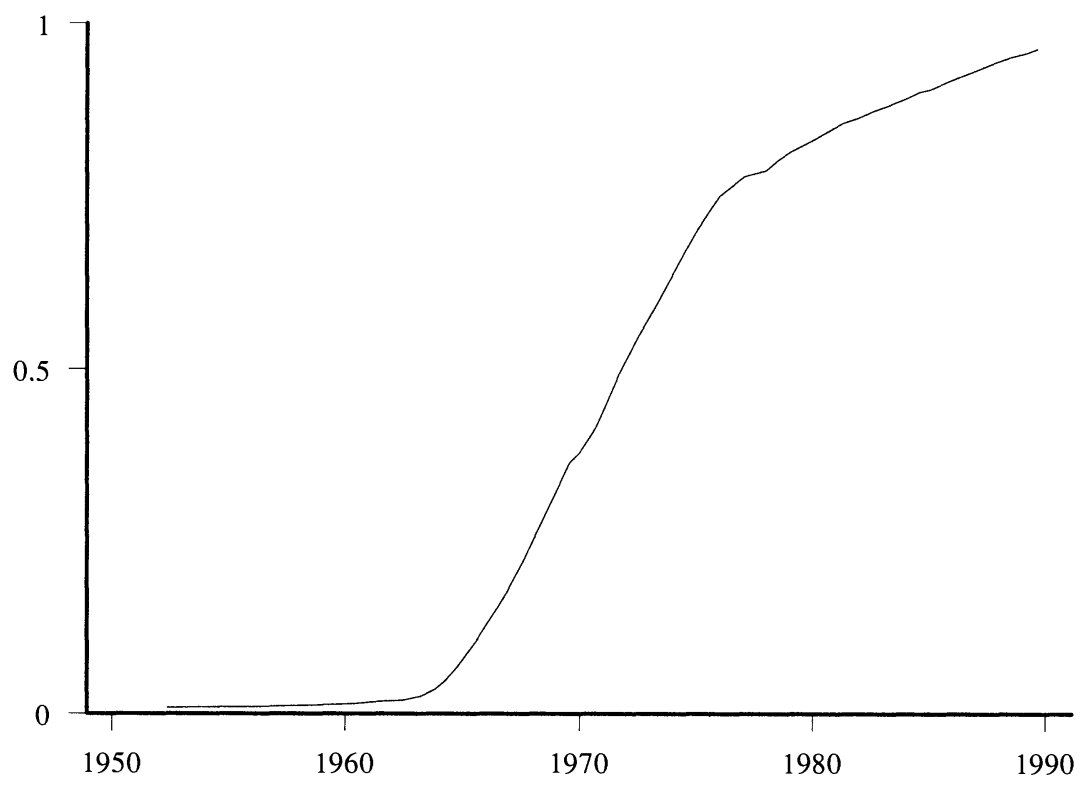

Source: Trends in Television. November 1990.

not already done so). During the 1960 s, color television sets were three to five times more expensive than were black and white sets.

\section{Adoption of Other Technologies}

Since we are aware of the limitations of the color television experience for assessing HDTV adoption, we have studied the adoption of four more recent technologies: cellular telephones, home video games, facsimile machines, and compact disk players. Each of these technologies has become a commercial success, although widespread adoption sometimes occurred many years after the technology was introduced commercially.

In each case, after sketching out the basic story of technology adoption, we suggest why some key elements of success seem not to be 
Figure 7. Hazard Rate on Color TV Set Purchases for TV Homes, 1954-90

Hazard rate

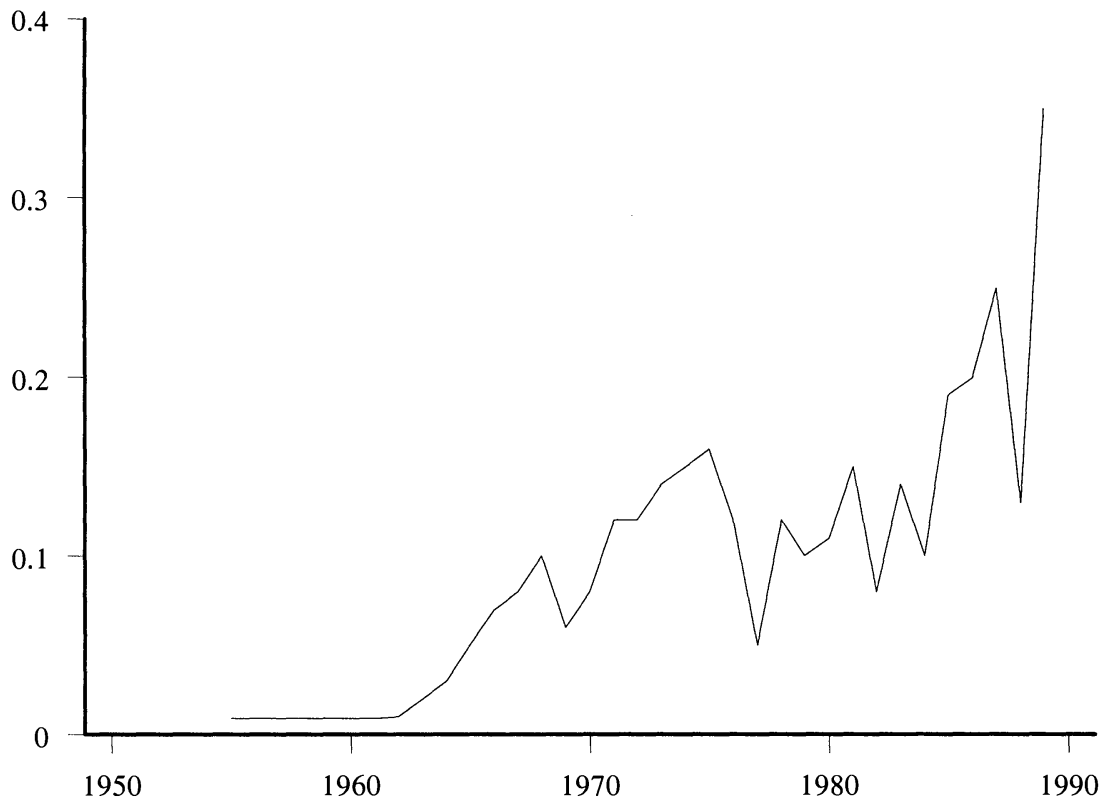

Source: Authors' calculations.

present in the case of HDTV. We stress, however, that each of these technologies differs from HDTV in so many ways that direct comparisons and or inferences about HDTV are extremely hazardous. In particular, the fact that all the technologies we look at here have become commercial successes does not mean that we think it necessarily appropriate to predict adoption of HDTV by analogy with successful products, as some have done. Rather, our goal is to use these examples to illustrate some general considerations in choosing technologies in network industries.

\section{Cellular Telephones}

Here we comment on the development of cellular telephone service and its implications for HDTV. ${ }^{81}$ The FCC was heavily involved in the development of cellular telephone systems. This was because the tech-

81. The material in this section draws heavily on Rosston $(1991,1992)$. 
nology uses the spectrum and requires interconnection to the main ("wireline") telephone network. Cellular telephone service is a major alternative user of the scarce spectrum space currently devoted to broadcast television.

Land mobile radio is communication involving mobile users via radio signals. Land mobile radio services can be broken into two types: private communication networks (police departments, taxicab fleets, and trucking companies) and cellular telephone systems (common carriers). Cellular systems are technically distinct from private networks: as a user moves from one "cell" to another, his or her call is automatically switched from the transmission and reception facility serving the first cell to that serving the second cell. The use of multiple cells greatly increases the capacity of a system since a single portion of spectrum can simultaneously carry different messages in different cells. Signals are broadcast at low power to prevent interference among cells.

One lesson from the cellular experience is that the FCC process of spectrum allocation and standard setting is lengthy. AT\&T proposed high-capacity mobile telephone service as early as the 1940s. In 1970 the FCC reallocated UHF channels 70 through 83 to land mobile radio service. Of the $115 \mathrm{MHz}$ total bandwidth reallocated, $75 \mathrm{MHz}$ was to be made available for common carrier services. Throughout the 1970s there was ongoing discussion of how many systems to permit in each geographic area, who should be chosen to operate these systems, and what technical standard to pick. At the end of the decade, two developmental cellular systems were authorized by the FCC and constructed. Based on the experience of these two systems, the FCC decided in 1981 to license two carriers in each area. It gave each carrier $20 \mathrm{MHz}$, with one license reserved for a local wireline carrier. Starting with the top markets and working down to smaller markets, the FCC actually assigned cellular licenses in the early 1980s. Cellular service arrived gradually. In 1986 each carrier was assigned an additional $5 \mathrm{MHz}$, in part because the systems in heavily populated areas were experiencing higher demand than had been projected.

The cellular telephone experience indicates the high value of UHF spectrum. The clearest evidence of the value of spectrum comes from the sales prices of cellular licenses. When cellular franchises change hands, their prices are typically quoted on a "per pop" basis. This is the dollar value of the franchise per person living in the franchise area. 
In 1991 a typical price per pop for a cellular system was $\$ 150 . .^{82}$ Of course, this price includes assets, such as paging equipment, other than the spectrum license alone. If these assets amount to $\$ 20$ per pop, the value of the spectrum is $\$ 130$ per pop. Is this a lot? Consider Los Angeles, the second largest market in the United States. With a population of about 13 million people, the value of each license is about $\$ 1.7$ billion. Since the license involves $25 \mathrm{MHz}$, or the equivalent of about four UHF channels at $6 \mathrm{MHz}$ each, the marginal value in Los Angeles of one UHF slot on the spectrum comes to about $\$ 400$ million. ${ }^{83}$

We realize that this back-of-the-envelope calculation is subject to many objections. ${ }^{84}$ Nonetheless, it seems to us that the magnitudes involved are highly suggestive. One cellular system using today's analog technology can serve about 300,000 subscribers. In Los Angeles this amounts to a bit more than 2 percent of the population; the two current systems can serve perhaps 5 percent of the population. If significantly more than 5 percent of those in Los Angeles demanded cellular telephone service at a price that included a smaller premium for spectrum rents, the UHF spectrum would have a high alternative use, at least in Los Angeles and on the margin. Tying up large amounts of UHF spectrum for HDTV could be quite costly socially.

Our calculations do not account for ongoing technological progress. It is not clear to us, however, how the marginal value of UHF spectrum will change as a result of innovations in the near future. First, signal compression techniques for land mobile radio, and a possible shift from analog to digital systems, are likely to permit cellular systems to increase the number of subscribers they can handle with their current allotment of spectrum. ${ }^{85}$ But will these technical developments increase

82. "POP Out: The Changing Dynamics of the Cellular Telephone Industry,' U.S. Investment Research, Telecommunications Services, Morgan Stanley, April 23, 1991.

83. The value of spectrum for cellular service would be scaled down in less populated areas, but so would the value of UHF service.

84. For example, the market value of a third franchise is presumably less than the first two. These market value measures, however, ignore all consumer surplus associated with cellular service.

85. According to Anthony Ramirez, "Worries Accompany Growth for Cellular Phone Industry," New York Times, February 14, 1992, p. D6, digital methods will triple the capacity of cellular systems. But there are serious obstacles to the introduction of digital systems, not the least of which is that existing analog handsets are incompatible with digital transmission methods. Since the heaviest users of cellular service already own analog equipment, this is a major barrier for a digital system to overcome. 
or decrease the demand for spectrum? The answer depends upon the elasticity of demand for cellular services and the fraction of today's price of cellular services attributable to rent on scarce spectrum space. Second, there are new technologies under development that will increase, perhaps dramatically, the demand for scarce spectrum space. One example is "personal communications networks" - the next generation of cellular telephone service. The cells are smaller, the signals are less powerful, and the handsets are so small they can fit into a shirt pocket. Another up-and-coming example is interactive television, which allows consumers to issue shopping orders or participate in polls or games while watching television.

Even if spectrum currently devoted to television could be devoted to land mobile radio, such a reallocation may not be the best way to manage scarce spectrum. There may be other portions of the spectrum suitable for land mobile radio that currently are devoted to uses with even lower marginal value than UHF television service. For example, the FCC recently proposed making available about $200 \mathrm{MHz}$ of spectrum (around the 2,000 $\mathrm{MHz}$ point in the spectrum) as an "emerging technologies band" for uses such as personal telephones, mobile data services, and satellite message services. These frequencies are currently being used by railroads, electric utilities, and police and fire departments for microwave communications. ${ }^{86}$ Another possible source of additional spectrum for mobile communications purposes is the military. The military apparently uses its assigned spectrum far less intensively than do civilian users.

In sum, the cellular telephone experience suggests two lessons. First, FCC technology-selection procedures can be expected to be slow. Second, the spectrum used for television appears to have a high value in mobile communications applications.

\section{Video Games}

The market for home video games exemplifies intergenerational competition with network externalities. The analogy between video games and HDTV is far from perfect, but some insight can be gained into the dynamics of competition in the presence of installed bases.

86. Edmund L. Andrews, "Plan Would Give New Phones Big Swath of the Radio Band," New York Times, January 16, 1992, p. A1. 
In the late 1970s Atari, Inc., introduced the first home video game console ("hardware") that could play interchangeable game cartridges ("software'). In the peak year, 1982, Atari sold over 6 million consoles, and the second-ranked firm, Intellivision, sold over 1 million consoles. By 1984 about 25 million consoles had been sold, including about 14 million Atari consoles. Following the 1982 peak, however, the market crashed. Sales fell by more than 50 percent from 1983 to 1984, and again from 1984 to 1985 . The crash can be attributed to market saturation: most of the target population (especially pre-teen and teenage boys) bought consoles during the boom years of the early 1980s. ${ }^{87}$

Our analysis of intergenerational rivalry begins in 1985 when Nintendo introduced in the United States its Nintendo Entertainment System (NES), a second-generation home video game. Fortunately for Nintendo, many of the first-generation machines sold in the early 1980s were not still generating software sales circa 1985, and many were not being used at all, either because the owners of these machines had graduated to other forms of entertainment or because they had tired of playing the games that could be rendered on these consoles. In other words, Nintendo faced relatively little installed-base resistance.

Nintendo's system quickly became a great commercial success. In round numbers Nintendo's console sales rose from 50,000 in 1985 to half a million in 1986, to 2.5 million in 1987, to over 9 million in 1989 , the peak. ${ }^{88}$

What does this rapid success tell us about the ability of a new technology to quickly displace an older, incompatible installed base? To begin with, the NES offered graphics and sound capabilities that were far superior to the first-generation machines. As a consequence, Nintendo faced relatively little resistance based on an active installed base: those target customers who did own and play first-generation machines were very willing to pay for Nintendo's improved quality, and many target customers did not even own first-generation machines because they had been too young to buy them.

Nintendo also benefited from having already successfully introduced

87. These data are taken from various press reports on the video game industry. Many of these reports rely on data provided by the NPD Group's "Toy Market Index."

88. These numbers are from Nintendo press releases. 
its "Famicom" system in Japan in 1983. Famicon was essentially equivalent to the system introduced in the United States. In part because of the Famicom system, Nintendo enjoyed close relationships with Japanese game developers and publishers who played a critical role in providing hit games for the NES. In addition, Nintendo actively promoted its system, hoping to appropriate the rewards of successful product introduction.

Our discussion so far has focused on intergenerational competition. Nintendo also faced limited competition from two other firms selling second-generation machines: Sega and Atari Corporation. In this intragenerational rivalry Nintendo enjoyed some initial advantages: it was the first firm to introduce a second-generation system, it had the ties to programmers already mentioned, and it published a few very popular games, most notably Super Mario Brothers, for play exclusively on its system. By 1989 Nintendo was able to parlay these initial advantages into complete dominance of the video game market. It sold about 90 percent of all consoles in that year. ${ }^{89}$

Our story does not end there, however. In 1989 Sega and NEC each introduced third-generation machines: the Sega Genesis System and the NEC Turbo Grafx 16. (These are 16-bit machines, in contrast to the 8-bit NES machine.) These new systems can render even more complex games with more levels of play and sharper graphics. Sega's system is enjoying considerable success, despite Nintendo's introduction in the fall of 1991 of its own third-generation machine, the Super NES. One reason for Sega's success may be that its third-generation machine can play cartridges designed for its second-generation machines; Nintendo's Super NES is not compatible in this sense with the NES. According to its press reports, Sega sold more than 1.6 million Genesis System consoles in 1991.

Installed-base resistance to a new generation of equipment is far less in the video game industry than in the television industry. Essentially, the economic lifetime of video game hardware is much shorter than the economic lifetime of a television. Installed bases are not as durable in

89. As of this writing, it is an open question whether Nintendo's dominance was achieved lawfully. Atari Corporation has sued Nintendo for monopolization of the home video game market. One of the authors, Carl Shapiro, has been retained by Atari Corporation in that litigation. 
video games as in television. But the ability of new video games to achieve relatively rapid market acceptance does not mean that HDTV penetration will be comparably quick.

Nintendo enjoyed many advantages circa 1986 that HDTV will not enjoy circa 1996: Nintendo offered a great improvement in quality over the previous generation of equipment; Nintendo had a prearranged and assured source of programming; Nintendo faced a significant population of target customers who did not own first-generation equipment; and Nintendo had only to convince distributors (retailers) to carry its machines, not to incur large sunk costs. In contrast, it is far from clear that HDTV is a dramatic improvement over NTSC as measured by consumers' incremental willingness to pay. There is no prearranged supply of HDTV programming, virtually all target HDTV customers own perfectly good NTSC sets with considerable remaining lifetime, and broadcasters will need to make large specific investments to broadcast HDTV. In short, we do not believe the rapid market penetration of second-generation home video games between 1986 and 1990 suggests that HDTV is likely to enjoy comparably rapid penetration.

\section{Facsimile Machines}

Facsimile machines are a dramatic recent example of how a network technology can suddenly take off and become a commercial success. Today's high-speed facsimile (or fax) machines are akin to HDTV in that their quality (especially as measured by speed) is superior to that previously available for timely transmission of documents. But the striking recent success of fax machines in the United States does not necessarily portend comparable success for HDTV.

As table 1 shows, fax machines got off to a very slow start in the United States. ${ }^{90}$ The intensity of use of fax machines rose markedly as the network of machines became larger, but then it fell off as less intense users joined the network, especially as individuals obtained their own fax machines instead of sharing them in large groups (figure 8).

The first generation of machines, known as Group 1 machines, appeared in the United States in the late 1960s. Incompatible machines

90. We are grateful to George Stamps of GMS Consulting Company for providing us with this data. 
Table 1. Intensity of Use of Facsimile Machines in North America, 1966-90

\begin{tabular}{|c|c|c|c|}
\hline Year & $\begin{array}{l}\text { Pages sent } \\
\text { (millions) }\end{array}$ & $\begin{array}{c}\text { Total installed } \\
\text { base } \\
\text { (thousands) }\end{array}$ & $\begin{array}{c}\text { Pages sent } \\
\text { per } \\
\text { machine } \\
\text { (per year) }\end{array}$ \\
\hline 1966 & 1 & 2 & 500 \\
\hline 1967 & 2 & 4 & 500 \\
\hline 1968 & 3 & 5 & 600 \\
\hline 1969 & 6 & 10 & 600 \\
\hline 1970 & 12 & 19 & 632 \\
\hline 1971 & 23 & 40 & 575 \\
\hline 1972 & 37 & 62 & 597 \\
\hline 1973 & 54 & 83 & 651 \\
\hline 1974 & 75 & 94 & 798 \\
\hline 1975 & 105 & 112 & 938 \\
\hline 1976 & 133 & 122 & 1,090 \\
\hline 1977 & 169 & 135 & 1,252 \\
\hline 1978 & 235 & 167 & 1,407 \\
\hline 1979 & 423 & 208 & 2,034 \\
\hline 1980 & 703 & 245 & 2,869 \\
\hline 1981 & 1,021 & 286 & 3,570 \\
\hline 1982 & 1,483 & 336 & 4,414 \\
\hline 1983 & 2,157 & 400 & 5,393 \\
\hline 1984 & 3,139 & 472 & 6,650 \\
\hline 1985 & 4,567 & 593 & 7,702 \\
\hline 1986 & 6,645 & 766 & 8,675 \\
\hline 1987 & 9,668 & 1,368 & 7,067 \\
\hline 1988 & 13,192 & 2,756 & 4,787 \\
\hline 1989 & 18,000 & 4,263 & 4,222 \\
\hline 1990 & 26,235 & 5,787 & 4,533 \\
\hline
\end{tabular}

Source: GMS Consulting Company.

were marketed by Xerox, Magnavox, and others even though the Electronics Industry Association had published its RS-328 standard for facsimile equipment in October 1966. ${ }^{91}$ In 1974 the Comité Consultatif International de Téléphone et Télégraph (CCITT) adopted a modified version of the EIA standard as an international standard. Because the CCITT had to lower the frequency range to fit into the shorter European

91. The FCC played no active role in the establishment of fax standards. FCC approval was required, however, to permit these machines to be hooked into the public telephone system. 
Figure 8. Pages Sent per Fax Machine, 1966-90

Total pages per installed base

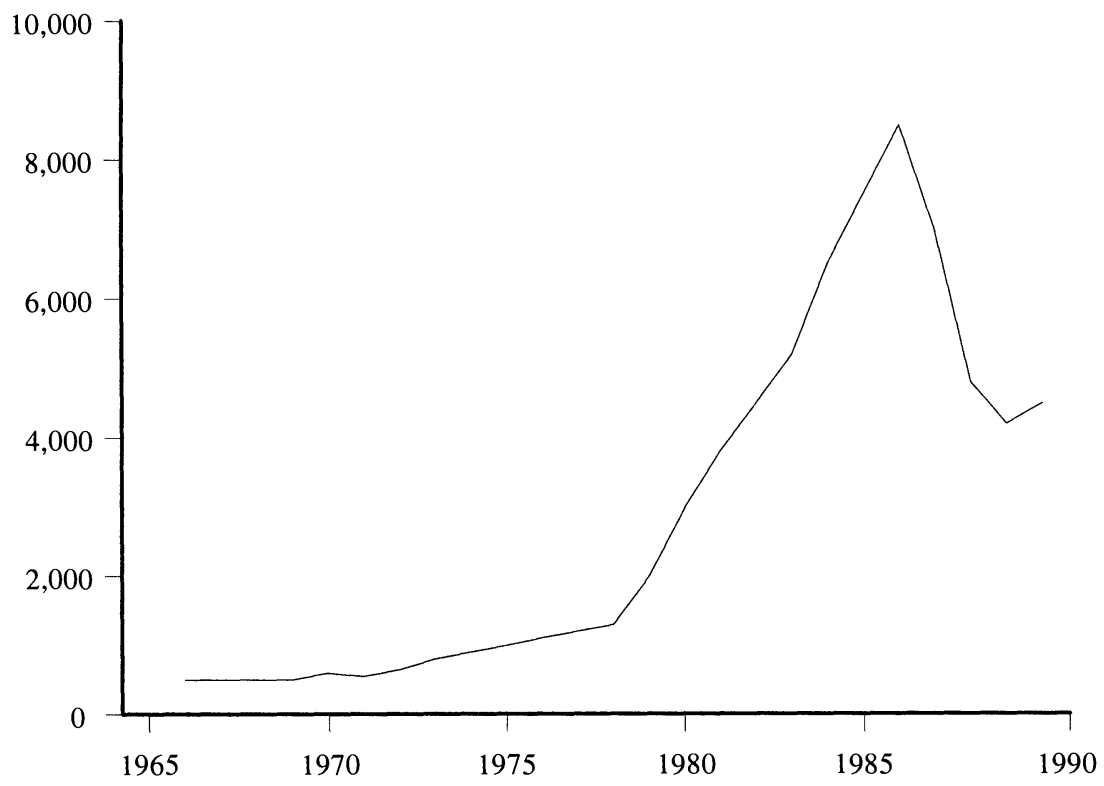

Source: Authors' calculations.

bandwidth, Group 1 machines in the United States could not communicate with Group 1 machines in Europe and Japan. Perhaps because it took them six minutes to transmit one page, Group 1 machines were never much of a commercial success. At their peak in 1979, only 142,000 Group 1 machines were installed in North America (table 2).

In 1971 Group 2 machines were introduced that could transmit one page in three minutes, twice as fast as the Group 1 machines. In 1976 the CCITT adopted standards for Group 2 machines. For the first time office facsimile machines were compatible worldwide. Despite the establishment of a worldwide standard and despite their faster speed, Group 2 machines met with limited success in the United States. The installed base of Group 2 machines peaked at 180,000 in 1984. One reason for the unimpressive sales of Group 2 machines is that superior Group 3 machines came quickly on their heels.

In the mid-1970s efforts were under way to replace analog fax systems (Groups 1 and 2) with a digital fax system (Group 3). By 1979 a 
Table 2. Installed Base of Facsimile Machines in North America, 1966-90

Thousands of machines

\begin{tabular}{|c|c|c|c|c|c|}
\hline \multirow[b]{2}{*}{ Year } & \multicolumn{4}{|c|}{ Group } & \multirow[b]{2}{*}{ Total } \\
\hline & 1 & 2 & 3 & 4 & \\
\hline 1966 & 2 & 0 & 0 & 0 & 2 \\
\hline 1967 & 4 & 0 & 0 & 0 & 4 \\
\hline 1968 & 5 & 0 & 0 & 0 & 5 \\
\hline 1969 & 10 & 0 & 0 & 0 & 10 \\
\hline 1970 & 19 & 0 & 0 & 0 & 19 \\
\hline 1971 & 40 & 0 & 0 & 0 & 40 \\
\hline 1972 & 61 & 1 & 0 & 0 & 62 \\
\hline 1973 & 81 & 2 & 0 & 0 & 83 \\
\hline 1974 & 89 & 5 & 0 & 0 & 94 \\
\hline 1975 & 104 & 8 & 0 & 0 & 112 \\
\hline 1976 & 111 & 10 & 1 & 0 & 122 \\
\hline 1977 & 119 & 13 & 3 & 0 & 135 \\
\hline 1978 & 132 & 28 & 7 & 0 & 167 \\
\hline 1979 & 142 & 51 & 15 & 0 & 208 \\
\hline 1980 & 141 & 81 & 23 & 0 & 245 \\
\hline 1981 & 131 & 118 & 37 & 0 & 286 \\
\hline 1982 & 120 & 153 & 63 & 0 & 336 \\
\hline 1983 & 106 & 176 & 118 & 0 & 400 \\
\hline 1984 & 90 & 180 & 201 & 1 & 472 \\
\hline 1985 & 77 & 162 & 347 & 7 & 593 \\
\hline 1986 & 43 & 149 & 567 & 7 & 766 \\
\hline 1987 & 15 & 100 & 1,243 & 10 & 1,368 \\
\hline 1988 & 5 & 55 & 2,681 & 15 & 2,756 \\
\hline 1989 & 1 & 26 & 4,216 & 20 & 4,263 \\
\hline 1990 & 0 & 14 & 5,743 & 30 & 5,787 \\
\hline
\end{tabular}

Source: GMS Consulting Company.

flexible Group 3 standard was agreed upon at the CCITT. ${ }^{92}$ Group 3 machines can transmit one page per minute, three times as fast as Group 2 machines. Eventually, Group 3 machines achieved enormous commercial success. By 1990 the installed base of these machines in North America had grown to 5.7 million.

Group 4 machines are completely digital and can transmit a page in

92. The Group 3 standard was proposed by the Japanese delegation. In the mid to late 1970s, Japanese companies were much more bullish on fax than were their American counterparts. 
a mere 10 seconds. They operate on integrated standard digital networks (ISDN). The standard-setting process for Group 4 was not as smooth as for Groups 2 and 3; a standard involving three classes of machines was adopted in 1984. To date, ISDN is more established in Europe and Japan than it is in the United States, which may be why Group 4 machines have had limited success in the United States.

What can we learn about HDTV from the fax experience? Will HDTV be a dud as Group 1 and Group 2 fax machines were, or will it be a success like Group 3 machines? To answer this requires an understanding of why Group 3 machines succeeded. Certainly, the early adoption of an international standard contributed to the success. But Group 2 had this same advantage. It appears to us that the improved quality of Group 3 machines (in conjunction perhaps with declining prices for long-distance telephone service) was enough to launch a successful bandwagon for Group 3 machines.

The equilibrium adoption path of a network product may be extremely sensitive to the quality of the product (or the cost of complements). To the extent that products either take off or flop, there must be a range within which demand is, in some sense, extremely elastic. A compromise in the quality of an HDTV system could be the death knell for HDTV. Or perhaps the lesson for HDTV is that costs must be rigorously held down. A more optimistic lesson is that the sluggishness of HDTV standard setting in the United States, by allowing the selection of a digital system superior in quality to analog systems such as HiVision, could help HDTV to triumph in this country.

Without a doubt, Group 3 fax machines had advantages that HDTV will lack. First, for fax machines there was no need to develop a supply of programming and a means of distributing it to users: end users have their own material to transmit and can deal directly with one another. Second, fax standards were set to ensure intergenerational as well as international compatibility, unlike HDTV.

Between 1979, when Group 3 standards were established, and the 1985-90 period, when fax machines really took off in the United States, there was a significant lag. Perhaps this lag resulted from the speedy and relatively smooth standard-setting process for fax, but it also serves as a reminder that market adoption can be a sluggish process after a standard has been picked. 
Table 3. Annual Sales in the United States of Compact Disk Machines and Disks, 1983-90

\begin{tabular}{ccccc}
\hline Year & $\begin{array}{c}\text { Compact disk } \\
\text { machines } \\
\text { (thousands) }\end{array}$ & $\begin{array}{c}\text { Installed } \\
\text { base } \\
\text { (thousands) }\end{array}$ & $\begin{array}{c}\text { Compact } \\
\text { disks } \\
\text { (millions) }\end{array}$ & $\begin{array}{c}\text { Number of } \\
\text { titles } \\
\text { available }\end{array}$ \\
\hline 1983 & 50 & 50 & 1 & 403 \\
1984 & 200 & 250 & 6 & 1,862 \\
1985 & 850 & 1,100 & 23 & 4,319 \\
1986 & 1,664 & 2,764 & 53 & 6,518 \\
1987 & 2,805 & 5,569 & 102 & 11,803 \\
1988 & 3,241 & 8,810 & 150 & 22,704 \\
1989 & 3,902 & 12,712 & 207 & 35,341 \\
1990 & 4,022 & 16,734 & 287 & 46,700 \\
\hline
\end{tabular}

Source: Recording Industry Association of America; see also text, note 94.

\section{Compact Disks}

A new, superior incompatible technology for recording and playing music was introduced in the United States in 1983: compact disks (CDs). To hear CD sound, a consumer needs a CD player ('deck'), a collection of disks, and an amplifier and other standard equipment. This is a "systems market" with the same complementarity structure as HDTV: consumer hardware and a supply of "programming"' are needed.

The market for CD technology has been characterized by falling prices for decks (hardware) and for CDs (programming). Sales and installed bases of hardware have increased rapidly, as has the selection of software available. We obtained data from the Recording Industry Association of America (RIAA) on annual sales, by volume and dollar value, of $\mathrm{CD}$ players and of CDs. ${ }^{93} \mathrm{We}$ also obtained annual data on the number of CD titles available - a measure of the variety of available " "programming.", 94 We then constructed price series for decks and for CDs by dividing dollar sales by sales volume. All the series except prices grew rapidly, and nominal prices fell, although less rapidly (tables 3 and 4 and figure 9).

The correct measure of demand for CD technology is not the current-

93. See especially RIAA, Inside the Recording Industry: A Statistical Overview, 1990.

94. Taking the last issue in each year of the New Schwann catalog, we sampled a variety of pages at random in different categories of music and counted how many titles were available on $\mathrm{CD}$ on each page. Incidentally, although (according to the RIAA) only about 5 percent of music purchases are classical music, roughly half of the available $C D$ titles were classical. 
Table 4. Average Retail Prices in the United States of Compact Disk Machines and Disks, 1983-90

Dollars

\begin{tabular}{lcc}
\hline Year & Deck price & Disk price \\
\hline 1983 & 750 & 21.50 \\
1984 & 518 & 17.81 \\
1985 & 311 & 17.23 \\
1986 & 258 & 17.55 \\
1987 & 207 & 15.61 \\
1988 & 201 & 13.96 \\
1989 & 218 & 12.49 \\
1990 & 177 & 12.05 \\
\hline
\end{tabular}

Source: Recording Industry Association of America.

year sales of CD players or decks, which are durables, but the total installed base. We constructed this variable and named it BASE. ${ }^{95}$ To represent the cost to a consumer of buying and using a $\mathrm{CD}$ system, (including the cost of a typical pattern of disk purchases as well as the initial price of the deck), we constructed a variable $B I L L .{ }^{96}$ This variable is a reasonable measure of the cost to a consumer of jumping on the $\mathrm{CD}$ bandwagon.

Strikingly, BASE rises by a factor of 334 over the sample period, while $B I L L$ falls only by a factor of two. Even if we omit 1983 and take the 1984-90 period, BASE rises by a factor of 67 , while BILL falls by a factor of two. If we believed that the fall in $B I L L$ drove the increase in demand, the implied elasticity of demand (measuring between 1984 and 1990) would be more than six. A regression of the $\log$ of BASE on the log of BILL yields an estimated demand elasticity of 6.4 .

These large elasticities, although possible, are unlikely. A significant share of the growth of demand was driven not by prices but by the greater variety of titles available on CD. Between 1984 and 1990, this measure of programming variety rose by an estimated factor of 25 .

95. In constructing BASE we assume that a negligible number of CD players were scrapped during our sample period. The variable $B A S E$ is then just the cumulative total of sales volumes.

96. First, we constructed a variable INTENSE, the number of CDs bought in any year divided by the base of decks present in that year. To construct $B I L L$ we then multiplied INTENSE by the price of disks (in that year) and multiplied by five to represent the notion that a consumer might expect to own a deck for five years and not have enormous foresight about prices; we then added in the price of a deck. 
Figure 9. Compact Disk Sales per Disk Player, 1983-90

Disks sold per installed base

24

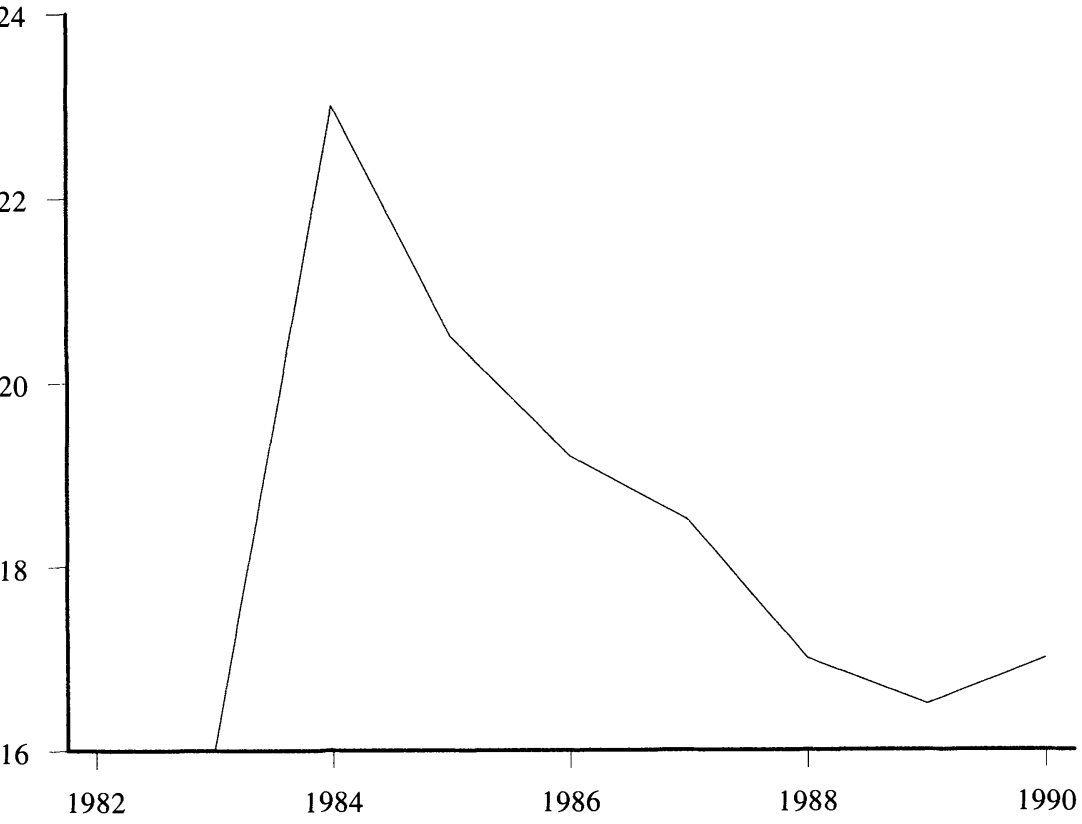

Source: Authors' calculations.

Remember that color programming hours were an important predictor of the hazard rate of households' color TV purchases. Provision of HDTV programming on the air is likely to be a major factor in driving consumer purchases of HDTV sets. Penetration forecasts cannot be made simply on the basis of predicted hardware prices. Of course, the number of titles available is likely to be driven by the installed base of sets (and expectations of the future path of that variable), as well as vice versa. A simultaneous-equations model would be required to explore properly the evolution of the industry.

\section{Digital Audio Tapes and Digital Compact Cassettes}

A sidelight cast by CDs on HDTV is in the transition from CDs to the next generation: digital tape. By the time CDs were commercially introduced, digital audio tape (DAT) was under development. Unlike compact disks, digital audio tape can be used for home recording. Much 
less affected by bumps and jars, it also can be used in Walkman-type players and in cars. DAT may be seen as a superior, incompatible technology that faces an installed-base problem in becoming established because of the lead that CDs took while this technology was being brought to market. Slow sales of DAT may be attributable to this incompatibility and installed-base disadvantage, as well as to the customary high prices of a new product. ${ }^{97}$

In 1991 Philips introduced a competing high-quality cassette technology, digital compact cassette (DCC). Although probably not the quality of DAT, DCC is likely to be cheaper. ${ }^{98}$ Moreover, DCC players will be able to play analog cassettes. Consumers investing in DCC will not have to abandon a cassette collection as they likely would with an investment in DAT. ${ }^{99}$

The threat to DAT from DCC and the threat to HDTV from EDTV may be analogous. In each case a simpler, cheaper, more compatible system can do much of what a more ambitious system can do, although its technical performance is not quite as good.

In the case of DCC and DAT, the market will decide which, if either, solution will prevail. ${ }^{100}$ In the case of EDTV and HDTV, the market may also decide, if the FCC sets an HDTV standard and if a fully compatible EDTV service, such as SuperNTSC, is implemented. In Japan ClearVision is reportedly popular and HiVision is still futuristic; in Europe PAL + (or even PAL) may be more popular than D2-MAC. Of course, there may be public policy aspects as well. For instance, the FCC could have decided to approve a form of EDTV and to ignore HDTV for the time being. ${ }^{101}$

97. Grindley (1992) argues that DAT could have been ready almost as soon as CD, but it was delayed in coming to market because of standard-setting problems and then because of industry fears that DAT would make it too easy to pirate recordings. Grindley (1992, p. 11) cites a sterling price equivalent to about $\$ 1,400$ for a DAT deck in the United Kingdom.

98. Grindley (1992, p. 6) cites a sterling price equivalent to about $\$ 400$.

99. According to the RIAA, cassettes have accounted for over half of unit sales of recorded music in every year since 1984 .

100. Quite possibly neither will succeed. It now may be hard to displace compact disks at the high end of the market, leaving DCC and DAT too expensive for the remainder. Grindley (1992).

101. On the question of whether the market is biased toward sticking with an established, compatible technology or switching to a new, technically superior, incompatible technology, see Farrell and Saloner (1985, 1986); and Katz and Shapiro (1986a, 1986b, 1992). 


\section{Prospects for HDTV Adoption}

Marketplace incentives for HDTV are seriously skewed so we cannot simply "ask the market" whether HDTV is worth the cost. The likely alternative is to adopt an EDTV system and wait until advanced television costs fall dramatically (as they well may after a decade of Japanese and European experience) or until superior systems emerge. The disadvantage of adopting a new system now is that once a system is adopted, the technology is in large part "embodied" and cannot readily be gradually improved. Had the United States been willing to wait a little longer in the 1950s, Japanese and American consumers might now be watching PAL-quality television. (Indeed, the drive for HDTV might then never have materialized.) Many Europeans now argue that adoption of the MAC family was too hasty and that they should wait until a superior all-digital system (or, at least, the underlying technology) emerges from the U.S. process.

Since the market will not answer these questions for us, we would like to answer them ourselves. Unfortunately, data on costs and benefits are elusive. ${ }^{102}$ Cost estimates vary wildly, and in many cases we suspect hidden agendas on the part of the estimators. ${ }^{103}$ Estimates of consumers' value from HDTV are also hard to obtain, although we have seen some survey data from MIT and from the North American High Definition Television Demonstrations to the Public in $1988 .{ }^{104}$ We have also viewed a simulation of broadcast HDTV reception, and while the resolution is certainly much better than NTSC resolution, we do not agree that it could be compared with 35 millimeter film.

Despite this, a number of market forecasts predict rapid growth of

102. We have been told that the Advisory Committee formulated an ambitious market research plan that was abandoned because it would have cost about $\$ 1$ million. Like the half-hearted funding of the ATTC, this suggests to us that the active participants are skeptical about the commercial value to them of HDTV, although in this case it could also reflect great confidence.

103. For example, Zenith has claimed very optimistically that HDTV receivers will be "no more than" \$500 more than NTSC. Electronic Business, August 20, 1990, p. 39.

104. These surveys show that most people (not all!) preferred HDTV to NTSC. Many participants said they would not spend more than a few hundred dollars extra for HDTV. Since it is likely to cost considerably more than that, the prospects do not look favorable if we believe these survey results. See Rice (1990, p. 172). He cites W. Russell Neuman, "'The Mass Audience Looks at HDTV: An Early Experiment,"' Massachusetts Institute of Technology, unpublished paper. 
the HDTV market. ${ }^{105}$ As others have pointed out, many of these forecasts rely on rules of thumb about market adoption rates, distilled from the experiences with successful electronics products!

It is possible that the surveyed consumers were reporting not their true willingness to pay, but their estimate of how much the incremental quality might cost. Many people are prepared to pay extra for better sets, such as IDTV, or larger sets. A different approach to demand prediction is to take a "characteristics" view. Since an average television household watches seven hours a day, if the incremental quality were worth 25 cents an hour, it would be worth over $\$ 600$ a year, or $\$ 3,000$ over a (conservative) five-year life for a set.

Despite these and other optimistic calculations, almost everyone agrees that the high price (at least initially) of HDTV receivers will cause the technology to be slow in taking off. Perhaps EDTV's threat to HDTV should be seen as an opportunity rather than an obstacle. An approach like Faroudja's SuperNTSC may be more likely to be adopted. Therefore, it may be more valuable than a technically superior system that could languish in drydock until it is outmoded. ${ }^{106}$

The lag between HDTV standard setting and HDTV set penetration is likely to be long. To some extent this is inevitable given the large and costly installed base of NTSC sets and the relatively long life of television receivers. If the HDTV lag is like the color lag, few Americans will buy HDTV sets this millennium. Sets will be bought only after programming and distribution are in place. Households are the least likely to try to take a leadership role in establishing a new technology.

We close on an optimistic note. The delay in setting a standard in the United States may lead to the development of significantly better technology. As a result, we doubt that a delay in setting the standard should be seen as a delay in the whole HDTV process. Instead, we suspect that adoption will catch up fairly soon with where it would have been without the delay. Once programming is available, adoption presumably will be determined by the cost of sets. This cost is determined more by technological progress in microelectronics and display man-

105. See, for instance, Congressional Budget Office, "Market Forecasts and HDTV's Impact on Other Industries,' in Rice (1990, chap. 4).

106. This view has been argued by NBC, somewhat to the FCC's annoyance after it set a full-blown HDTV process going. 
ufacturing technology, and perhaps by cumulative world experience in HDTV, than by the time since adoption of a national HDTV standard. A delay in setting a standard allows superior (cheaper) technology to be embodied in the standard. Thus, it is possible that the later (within reason) the FCC chooses a standard, the sooner HDTV may achieve (say) 20 percent penetration!

\section{Suggestions for the FCC}

In choosing among proposed HDTV technologies, the FCC (and its Advisory Committee) should recognize that ensuring a reasonably rapid adoption process depends upon reaching as quickly as possible the level of penetration at which programming suppliers and broadcasters and other media join the HDTV bandwagon in large numbers. In our analysis above, this tipping-point is represented by large values of the network externality ratio.

The FCC also should take seriously the need to use available information on the likely costs of the competing HDTV systems. If the commission finds it hard to learn directly about costs, it should consider some incentive-savvy method of eliciting true cost information from proponents. It can easily be worth enduring significant ex post inefficiency in order to incorporate private cost information into the choice of a standard, if sizable cost differences among systems are likely.

We are concerned about the large amount of spectrum that television, including HDTV, will occupy for years to come, especially under the FCC's favored simulcasting approach. Technological changes may increase the demand for the part of the electromagnetic spectrum that is suitable for ground-to-ground transmission, making alternative transmission of most television signals highly desirable. By moving toward a satellite-based television system, the Japanese and the Europeans are potentially reducing television's use of scarce terrestrial-broadcast spectrum. The United States should move in that direction as well. Indeed, because of cable's much higher penetration in the United States than in Japan or Europe, it should be easier for the United States to do so.

To satisfy today's terrestrial broadcasters, the FCC seems likely to 
adopt an HDTV system with no "headroom," that is, with no room to grow. This is very unfortunate. Squeezing HDTV signals into $6 \mathrm{MHz}$ will require sophisticated compression that adds costs to HDTV receivers and other equipment. It also may limit the ability of the HDTV system to innovate later on. 


\section{Comments and Discussion}

Comment by Richard R. Nelson: I enjoyed reading this paper. I started it knowing a bit about high-definition television and the issues involved. Now I have learned a lot more. My discussion will focus on three topics. The first is the possibility of long-run coexistence of two television systems - an updated old system and a new HDTV one. In my view the authors pay too little attention to this possibility. I then want to pick up a topic the authors deliberately do not discuss - policy toward HDTV as industrial policy. Finally, I want to consider the role of competition as the authors discuss it.

Most formal analyses of competition among new systems technologies presume or deduce that, ultimately, only one will survive. These analyses also tend to ignore existing systems for which the new are substitutes. Farrell and Shapiro certainly ignore the present system. Although there are places in their paper that hint to the contrary, virtually all of their analysis presumes that HDTV will ultimately replace even an improved version of what we have now.

If the cost of HDTV-receiving sets remains significantly above the cost of conventional sets, and if the quality of HDTV is not greatly better than that of enhanced-definition television (EDTV), many television viewers may prefer to replace their sets when they wear out with low-price EDTV sets, rather than with high-price HDTV sets. That proclivity will be enhanced if their sets can receive HDTV programming as well as EDTV programming. And in that context, if the broadcast equipment costs of HDTV continue to be very high relative to the costs of equipment for EDTV broadcasting, a number of broadcasters may decide not to get into the HDTV business.

This possibility jumps out at you from the verbal statements in the 
beginning of the paper. It seems to get lost, however, once the formal modeling takes over.

Assume that it happens, or at least that purchases of HDTV sets grow very slowly, as the authors suggest might well be the case. One then can see those who have invested in HDTV programming and broadcasting starting to press for regulations that would require that all new receiving sets be able to receive HDTV. Or, if that would not wash politically, and it probably would not, the pressure might be to drop requirements for reception compatibility. This might, or might not, lead to the demise of the EDTV system. In any case I think there are some interesting possibilities here, suggested by the authors' own statements, that require further analysis.

Let me turn next to the industrial policy issue and make two points. First, the HDTV case is an exemplary one for getting economists to recognize that there is a lot more to the workings of industry than competition and markets. In many sectors, not just television, government agencies are involved in what is happening and inevitably will shape developments for better or worse. In many industries and sectors government is an important actor as regulator, major customer, sponsor of certain activities, or provider of infrastructure.

Second, this involvement does not necessarily entail large subsidy or protection, much less attempts by a government agency to pick "commercial winners." In the case of HDTV many parties, prominently those connected with the U.S. semiconductor industry or interested in its viability, have argued that we ought to provide subsidies or protection or both for the development of a U.S. manufacturing industry involved in HDTV. The argument has been that HDTV is both a key technology in many future systems and a very major market in the future for semiconductors. Farrell and Shapiro cast doubt on both of these propositions.

I make these points for the following reason. Economists arguing against crude industrial policies of the "picking winners" sort have tended to downplay the inevitable role of government in many industrial sectors. It is quite possible to recognize the major role played by the government in many industrial sectors, but also to be more than skeptical about the effective role that government can play in leading commercial entrepreneurship.

Finally, I would like to remark upon the treatment by Farrell and 
Shapiro of the value of competition. In their formulation, competition is valuable in the early stages of a technology life cycle because it generates a variety of different proposed designs. Schumpeter would have nodded his head in assent. After a standard is set, or a dominant design comes into place, competition is valuable because it spurs efforts toward improvement and efficient operation. Although Farrell and Shapiro don't say this explicitly, it is clearly on their minds. I certainly would go along with these propositions. It is important to note, however, that the values of competition highlighted here are not at all the same thing as the value of competition in standard price theory.

All in all I find this paper refreshing and right-headed. I find it a useful contribution not only to our understanding of what is going on in HDTV, but also to a relatively new but now broadening literature that may be changing our views about what competition basically is about.

Comment by Roger G. Noll: For a decade the world television industry has been engaged in a fascinating race to develop the next technology for video display: high-definition television (HDTV). On the surface the motivation for the great HDTV race seems obscure at best. Its holy grail appears to be a three-foot by two-foot television set that will sell for several thousand dollars. This innovation will produce a better display, and it will allow viewers to watch wide-screen movies as they were originally filmed; however, for most consumers the incremental value of this quality advancement does not seem to be remotely near its costs. The puzzle, then, is why every advanced industrialized nation is sinking serious money into developing the technology.

The paper by Joseph Farrell and Carl Shapiro provides a meticulous analysis of the fundamental economics of HDTV technology and of the economic theoretic concepts that should guide a government-sponsored program to standardize a new network technology like this one. It also contains some assessment of the winners and losers of the process that has been adopted, concluding that once again commercial broadcasters seem to have won out.

I have no basic quarrel with Farrell and Shapiro concerning their conceptualization of either the economic issues that should guide the way technology choices are made or the problems facing policymakers 
in designing a technology race that will produce tolerably good results. My purpose here is twofold: first, modestly to expand the conceptual model of the economics and, especially, the politics of the HDTV race and, second, to provide some additional intellectual justification for this case study. Of course, both issues are related: the real reason to study the worldwide HDTV competition is because it provides a mean for testing and refining our understanding of both the economics of technological progress in network industries and the political economics of commercial $R \& D$ races that are controlled or directed by the government. In my view big puzzles are raised by this case. Why did the U.S. government pursue the policy option of a guided patent race (and why did other nations pursue the more conventional path of a centrally managed, subsidized R\&D project)? More fundamentally, why did any nation (or, for that matter, any company) bother sinking so much effort into a technology that seems to hold so little commercial prospect?

These puzzles become more focused when the HDTV program is viewed within the larger tapestry of, first, commercial $R \& D$ policy more generally and, second, the earlier history of attempts by the U.S. government to shape commercial technologies in the communications industry. Throughout the postwar era no large, advanced industrialized nation has been able to withstand the temptation to use regulation, subsidization, and procurement as instruments for shaping the development of new commercial technologies. Moreover, the choice of methods to influence commercial R\&D has differed among industries and technologies for reasons that do not appear to be based on the economic and technical characteristics of the technology.

During the Bush administration the U.S. government has tried to push the development of a variety of new commercial technologies. It is subsidizing SEMATECH to develop new manufacturing technology for the semiconductor industry. It is subsidizing the commercial aviation industry to develop the National Aerospace Plane (NASP). It is subsidizing "clean coal" technologies for electricity generation. In addition, the Bush administration has managed to cancel some other commercial $R \& D$ ventures that were favored by the Reagan administration. One was the rebirth in the Reagan era of the old communications satellite program aimed at developing direct broadcast satellites. Among the rest was a variety of ventures in microelectronics, communications, and computers that were being supported by the Defense Advanced 
Research Projects Agency (DARPA). And, earlier, Reagan rejected a program to subsidize the development of HDTV.

The choice of policy instruments available to the government has several dimensions. One is whether to develop the technology in the public sector or in private industry. Another is whether to pursue a centralized, fragmented, or competitive development strategy. A centralized strategy is one in which a single entity - a government lab, a single company, or an industry consortium-undertakes the project. Fragmentation refers to the practice of dividing the technology into components and letting different entities develop different parts, usually under the coordinating direction of a "prime contractor" (if private) or a "lead center" (if public). Still another is the type of development incentive offered: follow-on contracts, cost-sharing as work proceeds, or a prize for task completion.

In the case of HDTV, the original DARPA plan was to award conventional, competitively bid research contracts to a variety of companies, pursuing simultaneously several alternative paths of technical development. This approach is common, having been pursued initially in the NASP program, most energy technologies, and communications satellites. (In the last case Defense via AT\&T and NASA via Hughes pursued separate, single-contractor programs until the latter emerged as the clear winner.) However, in many cases a consortium approach is adopted, either initially or after an initial competitive period. For example, the NASP program, which began as a competition among several developers, soon evolved into a consortium involving all of the initial participants. In other nations the single-entity approach has been adopted for HDTV development.

When DARPA abandoned the field, the Federal Communications Commission (FCC) became the most important agency controlling HDTV development. The switch in agencies led to a switch in the incentive mechanism, from competitive bidding for contracts to a race for a prize: to become the standardized product for a commercial industry. By focusing solely on developments within the context of the last few years of the FCC standards competition, one can easily conclude that the issue is solely one of developing the next technology for commercial broadcasting. This assumption leads to using a rather narrow conceptual model to analyze the technology. The economic points of prime importance become compatibility and other issues associated with the 
transformation of a network industry from one technology to another. The political issue is historical FCC protection of the broadcasting industry, a debatable proposition recently in light of FCC policy regarding cable, syndication rights, and telephonic services. The difficulty with this approach is that it does not square with much of what we know, or can guess, about the prospects of the technology, and its political history as a policy issue. Why would HDTV be of interest to the Department of Defense? Why would Japan ignore completely the compatibility issue? And what kind of prize is it to become the standard technology for an industry that might never exist as a significant consumer product?

The most obvious alternative hypothesis is that creating home TV with a quasi-theatrical look is probably a red herring. Instead, perhaps the point of developing the technology has nothing to do with traditional broadcasting but with other uses. Examples of potential applications include far more effective remote monitoring, a means for implementing teleconferencing that enables an entire group around a table, rather than a single speaker, to be clearly visible to a remote conferee, and applications other than video of advances in signal compression and artificial intelligence that are byproducts of developing a digital HDTV system that does not devour enormous quantities of spectrum. HDTV may be simply a convenient vehicle for undertaking a new line of technical advancements that has very little to do with television.

This raises a problem for the Farrell-Shapiro analysis. Conceptualizing the economic problems as driven by the particular characteristics of television as both a network technology and a politically influential industry may be excessively narrow. If the point is remote sensing and chips capable of signal compression and artificial intelligence, the importance of backward compatibility shrinks dramatically, and the threat posed to either commercial broadcast interests or owners of conventional television sets is minimal. What is at stake if the game is not for the future TV market is, instead, designation as the leader for future defense contracts. Moreover, the industry that may have the most at stake is not broadcasting but telephony. For if the most likely use of the technology is private, rather than public, video transmission, the commercialization issue becomes whether the medium will be the fiberoptic network of telephone companies or the electromagnetic spectrum with its myriad users. Of course, if the answer is the telephone 
company, standardization (but not backward compatibility) is a necessity. If the answer is a fragmented industry (like most private uses of the spectrum), the desirability of a ubiquitous common standard is less clear, although by no means ruled out.

Notice how these possibilities affect the theoretical model developed by Farrell and Shapiro. In the broadcasting industry the two overriding characteristics are, first, the fact that broadcasts are a public good and, second, the economic advantages of standardization. The import of the first is that an increase in viewers within the service area of a television station does not increase programming costs, but does increase station revenues. A more subtle economic consequence is that, in a competitive environment, the equilibrium quality and diversity of programs also increase with the number of viewers. In the Farrell and Shapiro model this factor is taken into account by assuming that the willingness to pay for a video technology rises with the number of people who use it. The mechanism through which this takes place is that the added revenue potential of a larger audience leads through competition to improvements in the quality dimension of programming.

Standardization is valuable because of the mechanism of delivery of the signal: simultaneous delivery of numerous video options over the same medium (airwaves or cable). Consumers do not care whether all of their newspapers, magazines, and books are printed in exactly the same format because the delivery mechanism provides no economic value to having all printed pages the exact same size and format. Consumers do care whether they can receive all available television stations on the same reception device because the delivery mechanism requires an expensive home receiver. A separate TV set for each station would be the expensive and wholly unnecessary result if several incompatible formats were used (as is the case in print media).

Viewing the problem this way leads naturally to the core problem raised by Farrell and Shapiro, and to the most interesting contribution of their paper. Specifically, to avoid wasteful investments in a competition among parallel technologies that eventually will lead to an industry in which one technology survives, the government can run a race for the dominant technology based solely on their performances at the end of the R\&D stage. Then through procurement or standardization, it can let only the winner enter the market. The problem for the government is to find a reasonable solution to the key trade-off 
problem: the incremental quality of the new has to be worth the incremental cost. The incremental quality includes not just reception quality, but also program characteristics and convenience of use. If the cost is so high that few subscribe, program quality will be lower. And if using the new technology requires separate reception systems for both new and old, convenience is lower than if the reception systems were compatible.

The single most important observation in the Farrell and Shapiro paper is that the system set up by the FCC is quite likely to do very poorly in identifying the optimal trade-off between reception quality and compatibility on the one hand and program quality on the other. The reason is that a standards race based solely on maximizing picture quality subject to a compatibility requirement ignores two aspects of the trade-off. The first is that the winning system will probably be substantially too costly because affordability is not a criterion. The second is that some sacrifices of complete compatibility may be worthwhile if they significantly reduce costs. For example, asymmetric compatibility (HDTV sets must be able to receive normal TV broadcasts, but normal TV sets need not be capable of receiving anything at all from some HDTV stations) might so reduce costs that everyone would buy HDTV and thereby moot the incompatibility that was permitted.

To sharpen the incentives for the standards race, the FCC needs to incorporate the trade-offs among reception quality, compatibility, and costs/penetration/program quality. Here the problem is that costs are probably not observable to the government until after the winner has been declared and the system has been introduced. Farrell and Shapiro focus on the cost-reporting aspect of the problem, but a more vexing issue is the value to consumers of technical attributes of the new technology. Even if the FCC adopted a method for eliciting reliable best estimates of costs, it would still need to know how to trade off costs versus qualitative attributes. But as Farrell and Shapiro state, we also know that the FCC will not do this-and even if it did, it will face the sad reality that the technology is probably not worthwhile in the foreseeable future in the applications for which it is being tested. In this case the optimal design of the standards race is probably something very close to the following: the prize goes to the team that can double the size of a TV screen at present picture quality for the lowest cost, regardless of whether HDTV signals are backward compatible. But even 
this rule may produce a technological turkey-or enhanced-definition television (EDTV) instead of HDTV, as the authors suggest.

Farrell and Shapiro, then, are dead right when they conjecture that the design of the FCC process appears to convert a technological long shot into an assured failure for its stated purpose. But this leaves a major remaining puzzle: why are so many private, for-profit companies engaging in the charade? Of course, not knowing the facts I cannot offer more than speculations. But let me list a few, and then show how these affect the kinds of economic and political analysis that one would tackle to explain and predict the design and outcome of this policy.

Conjecture No. 1: The purpose is a new distribution system for theatrical productions. The potential market for HDTV, in this case, consists of theaters (for closed-circuit events, such as some major sporting events or one-time entertainment extravaganzas) and perhaps bars and restaurants (for a new form of pay-per-view). The cost per receiver is too high for consumers. Therefore, what the industry is really after is a vastly improved means for distributing Monday night football and heavyweight championship events. The distribution system could be by satellite, avoiding the necessity of a major investment in a massive new terrestrial broadcast system. Bars and theaters, unlike either consumers or broadcasters, would find the technology something other than a prisoner's dilemma if it succeeded in significantly increasing attendance at group-consumed events. In this case the backward compatibility requirement and the design of a system to maximize reception quality ensure that the use will not be conventional broadcasting to the home, and even may make sense as a means to take account of the network externality among the group of potential customers. (A bar is not likely to care if a receiver costs $\$ 5,000$ instead of $\$ 2,000$ as long as it has a far better picture and draws more customers.) More generally, for group consumption of program material, even an expensive technology will have a relatively small fraction of its costs associated with hardware compared with program material, and only a small part of these reception costs is marginal. Consequently, even a relatively small elasticity of demand with respect to quality will result in a very high-quality system.

Conjecture No. 2: The objective is video distribution over wire/ fiberoptic networks. Under this scenario the point of the constraints placed on the standards development process is to ensure that the tech- 
nology is not used off-air, but exclusively on either cable or telephone networks. Signal compression technologies modestly stack the deck in favor of nonfiber ISDN - that is, digital transmission at high bit rates, but not so high that they cannot be accommodated on copper wire or coaxial cable. Under this regime the sub rosa distributional objective is hardly protective of broadcasters. Instead, it improves the capability of existing cable and telephone networks to compete against off-air broadcasters. Forcing only the last to ensure backward compatibility puts them at a distinct disadvantage.

This scenario seems broadly consistent with the FCC's overall vision of communications, which is eventually to have a far larger wire-based communications system delivering a vast array of unspecified but wonderful new information services. Essentially all observers, including the main beneficiaries on the supply side (telephone companies), believe that a necessary condition for the emergence of the electronic umbilical is that video entertainment switch to the telephone system. Otherwise, the very high fixed costs of a high-speed, high-capacity terrestrial network cannot be recovered. (Literally all communications have to travel over the network to get the average costs down to something a consumer might pay for.) Under this regime not only is backward compatibility something to ensure that broadcasters will be unable to get in the way of the vision by offering HDTV in competition with the telephone company, but it also gives the FCC an excuse to tie up the UHF spectrum, relieving political pressure to reallocate spectrum to radio telephony.

The big danger from radio telephony is that, if offered by a competitive industry without the capability for mobility (other than walking around the house and yard), its price might be sufficiently low that telephone companies would lose large numbers of customers for ordinary telephone service, especially if telephone access tariffs are forced up to pay for a major investment in upgrading the network to ISDN capability. Defections to radio telephony would undermine the vision of the electronic umbilical by removing basic access charges as a means for covering a major share of the fixed costs of HDTV transmission (and other enhanced services).

Thus, the HDTV standards race can be interpreted as biasing the bigger race concerning the overall structure of the communications industry in favor of a terrestrial ISDN monopoly. The willingness of hardware manufacturers to participate is more understandable in this 
case, for what is at stake is developing the technology that will be sold to telephone companies, which can be expected to provide cross-subsidized services using the technology should this prove necessary in order to justify ex post the regulatory policies that advantaged them.

Conjecture No. 3: HDTV is still a DARPA program. DARPA wanted to control the HDTV development program because it envisioned a variety of uses of not only HDTV but of some of its components in advanced weapons systems. Especially interesting to DARPA are signal compression and the artificial intelligence chips necessary to reproduce an entire transmission from the compressed bit stream. In this case DARPA either does not care about commercial HDTV of any form, or perhaps wants to ensure that it never happens as a means of keeping secret some of the core components of the system. If the latter, the great HDTV race is simply the first stage in DARPA's triple crown, the next being refinements sponsored by DARPA and the last being weapons applications. If HDTV turns out to be a technological turkey as a commercial technology, DARPA need not worry about the commercial side carrying the work to its own version of the Preaknessprivate HDTV will not get past the Kentucky Derby and so will not pose a security threat to military uses of artificial intelligence in signal interpretation. In this case, of course, compatibility is the antithesis of the objective of the program, and the economics of network technologies, along with the politics of the communications sector, are irrelevant.

Conjecture No. 4: The HDTV race is the first stage in a process that will lead to a TV consortium or cartel. The point of the HDTV race is to define a U.S. system, not to implement it. A natural result of the process as designed is that a wonderful concept is announced, but it is too costly to have commercial prospects. Hence, the case emerges for a collaborative crash program to make breakthroughs in producing the components of the system that will lower its manufacturing costs. Thus, as with NASP, the Clinch River Breeder, the SST, and many programs before, stage two will be VIDTECH, a new industry-wide R\&D consortium to improve U.S. manufacturing technology in HDTV and in video technology more generally. A high-cost but high-quality technology, therefore, serves as the stalking horse for cartelization, sold as a means for effectively competing in the international marketplace.

Whereas none of these scenarios may be correct, they do have somewhat greater consistency with the facts of the HDTV program and with 
other government commercial $R \& D$ ventures than does the stated purpose of the program: to develop the next generation of commercial TV technology. Whereas no one should be surprised that the FCC did not adopt a Groves mechanism for eliciting truthful cost estimates, one should take seriously the fact that the FCC did adopt some ground rules for the HDTV race that are quite clearly at odds with the proposition that the FCC's objective is to produce HDTV for over-the-air broadcasting. Inferring the set of objectives that are consistent with these decisions strikes me as an interesting intellectual puzzle.

General Discussion A number of participants doubted the ability of the U.S. government to choose and enforce one HDTV standard. In particular, some discussants raised questions about the authors' analogy between the adoption of a single color television standard in the 1950s and the future adoption of an HDTV standard. Bronwyn Hall noted that today there are VCRs and cable television, which did not exist when the color television standard was adopted. Sam Peltzman felt that a better analogy could be made to VCRs-where two standards emerged without government intervention and competed successfully.

Several participants commented on the inability of the cable television industry to become a player in the battle to set an HDTV standard. Steven Salop said that because the cable industry is fairly concentrated, it should have the ability to organize itself and attempt to launch an HDTV system, preempting the broadcast industry. He claimed that the cable industry successfully collaborated in the past in launching new systems and program supplies. Richard Schmalensee conjectured that the cable industry's failure was in part attributable to its lack of political influence at the FCC.

Geoffrey Rothwell said that there is little reason why consumers would prefer HDTV alone over the current television system because the improvement in resolution is difficult to distinguish other than from very short distances. He said that HDTV should instead be viewed as the visual component within a whole new personal communications system that would integrate personal computers, telephones, and television. Bronwyn Hall, however, said that even the limited improvement brought about by HDTV should draw many consumers, particularly those interested in watching sporting events or pay-per-view television.

Schmalensee said that support for government sudsidization of HDTV 
development based on the belief that HDTV would lead to great benefits for the U.S. economy was misplaced. He said that many supporters of government subsidization assume unrealistically that HDTV would penetrate the U.S. market very rapidly and, more important, that all HDTV chips would be manufactured domestically, even though this is not the case for computers.

In commenting on the authors' presentation of royalty auctions, Ronald Braeutigam noted that the authors assumed a static world with fixed costs. He wondered what auctions would look like in a more realistic world with technological change and cost reductions over time.

Several participants discussed the effects of the presence of network externalities. Salop wondered if network externalities would create a need for a different type of property rights system, given the heightened possibility of monopoly power. Robert Willig suggested that for the HDTV case, network externalities would increase the ability of the market to make quality choices compared with government imposition of a standard.

George Borts wondered why the FCC had become such a powerful focal point for discussion about the future shape of HDTV. He said that the FCC should play some role in allocating a band spectrum for HDTV but should not be involved in determining HDTV technology.

Linda Cohen argued that political competition over modes of broadcasting, which exists in the United States but not in Europe and Japan, accounts for the differences in policy choices. In Japan and, to a lesser extent, Europe, direct satellite broadcasting is dominant, whereas in the United States there is competition among broadcast, cable, and future technologies such as fiber optics. According to Cohen, the inability of the U.S. government to impose an HDTV standard here, as was done in Japan and Europe, is a reflection of this competition. 


\section{References}

ANSI (American National Standards Institute). 1987. Procedures for the Development and Coordination of American National Standards.

Besen, Stanley M., and Leland L. Johnson. 1986. Compatibility Standards, Competition, and Innovation in the Broadcasting Industry. Santa Monica: RAND.

Borenstein, Severin. 1988. "On the Efficiency of Competitive Markets for Operating Licenses." Quarterly Journal of Economics 103 (May):357-85.

Crane, Rhonda J. 1979. The Politics of International Standards: France and the Color TV Wars. Norwood, N.J.: Ablex.

Donlan, Thomas G. 1991. Supertech: How America Can Win the Technology Race. Homewood, Ill.: Business One Irwin.

Ducey, Richard V., and Mark R. Fratrik. 1989. "Broadcasting Industry Response to New Technologies." Journal of Media Economics 2 (Fall):6786.

Farrell, Joseph, and Garth Saloner. 1985. "Standardization, Compatibility, and Innovation." RAND Journal of Economics 16 (Spring):70-83.

- 1986. "Installed Base and Compatibility: Innovation, Product Preannouncements, and Predation." American Economic Review 76 (December):940-55.

- 1992. "Converters, Compatibility, and the Control of Interfaces." Journal of Industrial Economics 40 (March):9-36.

Farrell, Joseph, and Nancy T. Gallini. 1988. "Second Sourcing as a Commitment: Monopoly Incentives to Attract Competition.' Quarterly Journal of Economics 103 (November):673-94.

FCC (Federal Communications Commission). 1988. “Tentative Decision and Further Notice of Inquiry.' Federal Communications Commission Record, $6520-53$.

\section{Television Service.}

Fishman, Daniel, and Elliot King. 1990. The Book of Fax. 2d ed. Chapel Hill, N.C.: Ventana Press.

Grindley, Peter. 1991. "Replacing a Product Standard: The Case of High Definition Television." Working Paper 100. Center for Business Strategy, London Business School.

- 1992. "Compact Disk and Digital Audio Tape: The Importance of Timing." London Business School. Mimeo.

Harris, Charon J. 1992. "Advanced Television and the Federal Communications Commission.' Federal Communications Law Journal, forthcoming.

Hatfield, Dale N., and Gene G. Ax. 1988. “The Opportunity Costs of Spectrum 
Allocated to High Definition Television.' Paper presented at Telecommunications Policy Research Conference. Hatfield Associates, Boulder, Colo.

House Committee on Energy and Commerce. 1989. Public Policy Implications of Advanced Television Systems. Staff report for the Subcommittee on Telecommunications and Finance.

Johnson, Leland L. 1990. Development of High Definition Television: A Study in U.S.-Japan Trade Relations. Santa Monica: RAND.

Katz, Michael L., and Carl Shapiro. 1985. "Network Externalities, Competition, and Compatibility." American Economic Review 75 (June):424-40.

- 1986a. "Product Compatibility Choice in a Market with Technological Progress." Oxford Economic Papers 38 (November supplement):146-65.

- 1986b. "Technology Adoption in the Presence of Network Externalities." Journal of Political Economy 94 (August):822-41.

- 1992. "Product Introduction with Network Externalities." Journal of Industrial Economics 40 (March):55-84.

Levy, Jonathan D. 1981. Diffusion of Technology and Patterns of International Trade: The Case of Television Receivers. Ph.D. thesis, Yale University.

Loeb, Martin, and Wesley A. Magat. 1979. "A Decentralized Method for Utility Regulation." Journal of Law and Economics 22 (October):399-404.

McConnell, Kenneth, Dennis Bodson, and Richard Schaphorst. 1989. FAX: Digital Facsimile Technology and Applications. Norwood, Mass.: Artech House.

National Association of Broadcasters. 1987. Tomorrow's TVs: A Review of New TV Set Technology, Related Video Equipment, and Potential Market Impacts, 1987-1995. Washington: NAB.

-1989. NAB Guide to Advanced Television Systems.

Nickelson, R. L. 1990. "HDTV Standards: Understanding the Issues." Telecommunication Journal 57 (May):302-12.

Office of Technology Assessment (U.S. Congress). 1990. The Big Picture: HDTV and High-Resolution Systems: Background Paper.

Rice, John F., ed. 1990. HDTV: The Politics, Policies, and Economics of Tomorrow's Television. New York: Union Square Press.

Rosston, Gregory. 1991. "Cellular Radiotelephone Regulation." Stanford University. Mimeo.

- 1992. "The Value of Cellular Telephone Licenses." Stanford University. Mimeo.

Senate Committee on Governmental Affairs. 1989. Prospects for Development of a U.S. High Definition Television Industry.

Shepard, Andrea. 1987. "Licensing to Enhance Demand for New Technologies." RAND Journal of Economics 18 (Autumn):360-68. 
Wassiczek, N., G. T. Waters, and D. Wood. 1990. “European Perspectives in the Development of HDTV Standards." Telecommunication Journal 57 (May):313-20.

Williamson, Oliver E. 1976. "Franchise Bidding for Natural Monopolies: In General and with Respect to CATV.' Bell Journal of Economics 7 (Spring):73104. 